\title{
LA HISTORIA COMO PASIÓN Y COMPROMISO. ENTREVISTA A ALICIA ALTED VIGIL
}

\author{
History as passion and commitment. \\ Interview with Alicia Alted Vigil
}

\author{
Gabriela Ossenbach Sauter ${ }^{1}$
}

Resumen. Entrevista a Alicia Alted Vigil, Catedrática de Historia Contemporánea en la Universidad Nacional de Educación a Distancia (UNED) de Madrid, especialista en el estudio del exilio republicano español de 1939. En la entrevista se aborda su trayectoria desde que se hiciera cargo en los años 1980 de la catalogación del archivo del gobierno republicano en el exilio, así como su especialización en el trabajo histórico con testimonios orales. Entre sus investigaciones en torno al exilio republicano, la entrevista destaca sus trabajos sobre las consecuencias del exilio y la guerra civil para la infancia.

Palabras clave: Exilio; Guerra civil; Segunda República; Infancia; Dibujos infantiles; Fuentes orales.

Abstract. Interview with Alicia Alted Vigil, Professor of Contemporary History at the Universidad Nacional de Educación a Distancia (UNED) in Madrid, a specialist in the study of the Spanish Republican exile of 1939. The interview addresses his career since she worked in the 1980s in the cataloging of the archives of the republican government in exile, as well as her specialization in historical research with oral testimonies. Her research on the consequences of exile and civil war for children stands out especially.

Key Words: Exile; Spanish civil war; Second Spanish Republic; Childhood; Children's drawings; Oral sources.

\footnotetext{
${ }^{1}$ Universidad Nacional de Educación a Distancia. Facultad de Educación. Juan del Rosal, 14. 28040 Madrid, España. gossenbach@edu.uned.es
}

Cómo citar este artículo: Ossenbach Sauter, Gabriela. «La historia como pasión y compromiso. Entrevista a Alicia Alted Vigil». Historia y Memoria de la Educación 9 (2019): 563-600. 
Alicia Alted Vigil ha sido una pionera y un referente en los estudios sobre el exilio republicano de 1939, tema en el que se inició en los años 1980 cuando se hizo cargo de la catalogación del archivo del gobierno republicano en el exilio. Su labor en este campo se ha centrado no solo en la publicación de numerosas investigaciones, para las cuales los testimonios orales han sido su principal fuente de estudio, sino también en la organización de reuniones científicas sobre el tema y en una amplia labor de difusión a través de exposiciones en las que ha prestado una especial atención a las consecuencias del exilio para la infancia. Desde que realizara su tesis doctoral sobre la política educativa y cultural del franquismo durante la guerra civil, ha seguido prestando atención al tema de la educación, lo cual se ha reflejado también en muchas de las tesis doctorales que ha dirigido sobre temas histórico-educativos.

Alicia Alted inició sus estudios en la Universidad Complutense de Madrid en el curso 1970-1971, y obtuvo la licenciatura en Geografía e Historia (Sección de Historia Contemporánea) en junio de 1975. De aquellos años guarda un especial recuerdo del profesor José María Jover, al que considera un gran maestro. En 1977-1978 hizo los cursos de doctorado, en los que tuvo como profesoras a María Victoria López Cordón y a Carmen García Nieto, de las que afirma que le encantaron "por su sensibilidad como mujeres y por su valía como investigadoras». Su primera publicación tuvo su origen en el trabajo de curso que hizo con la profesora López Cordón, un estudio en torno un periódico del siglo xvIII: El Apologista Universal. Con Carmen García Nieto empezó su formación en el ámbito de la recogida y utilización del testimonio oral como fuente para la investigación histórica.

Inició su carrera docente en 1975, en los Institutos Politécnicos de Formación Profesional «Juan de la Cierva» y «Vallecas I» de Madrid, trabajo que simultaneó con una beca de Formación de Personal Investigador que obtuvo en 1979 para realizar su tesis doctoral en la UNED. En 1982 pidió la excedencia en la Enseñanza Media y pasó a la UNED como Profesora Ayudante. En 1983 defendió su tesis titulada Política educativa y cultural del nuevo Estado durante la guerra civil española, 1936-1939. El Ministerio de Educación Nacional y sus antecedentes, publicada por el Ministerio de Cultura en 1984. En 1986 aprobó la oposición de Profesora Titular en el departamento de Historia Contemporá- 
nea de la UNED, dirigido a la sazón por el profesor Javier Tusell, y en 2011 accedió a una cátedra en el mismo departamento.

Su memoria de licenciatura versó sobre la figura de Pedro Sainz Rodríguez, que luego estudiaría en profundidad en su tesis doctoral. Fue un trabajo que formó parte de una iniciativa surgida entonces en el departamento de Bibliografía de la Universidad Complutense, referida al estudio de la labor llevada a cabo por catedráticos ya jubilados que habían pertenecido a dicho departamento, entre los que figuraba $\mathrm{Pe}$ dro Sainz Rodríguez. Esta investigación (Biobibliografía crítica de Pedro Sainz Rodríguez, 1977) le permitió conocer y trabajar sobre la personalidad y la obra de un hombre que tuvo un significativo protagonismo en la historia española reciente. Le conoció personalmente en 1977 y, desde ese año hasta su muerte, en diciembre de 1986, mantuvo un trato continuado con él y pudo consultar libremente el espléndido archivo y biblioteca que conservaba en su casa del Parque de las Avenidas en Madrid, así como en la casa de Consuelo Gil Roësset, en la madrileña plaza del Cordón.

Explica Alicia Alted que cuando estudió en la universidad la historia contemporánea de España nunca llegó a la guerra civil, y por supuesto no estudió nada del franquismo ni del exilio. Concluyó sus estudios, pues, con grandes lagunas sobre aspectos del pasado inmediato, lo que le llevó a orientar sus estudios hacia esos temas. La historiadora Carmen García Nieto la puso en contacto indirecto con Manuel Tuñón de Lara, de quien ella hablaba muchas veces en su curso de doctorado, valorando la importancia de los famosos Coloquios de Historia Contemporánea de España que Tuñón organizó entre 1970 y 1980 en la Universidad de Pau. Tiempo después Alicia Alted pudo conocer personalmente a Tuñón de Lara, que estuvo como miembro del tribunal de su oposición a la plaza de Profesora Titular. Asistió a los coloquios que Tuñón organizó en Madrid, Segovia y Cuenca cuando regresó a España y después coincidieron en diversas actividades que se organizaron en esos años.

Según relata Alicia Alted, nunca se sintió atraída por la historia política basada en acontecimientos, porque lo que le interesaban eran las personas, el trasfondo de sus actuaciones, las cuestiones sociales y culturales, los aspectos de la vida cotidiana, todo ello desde una perspec- 
tiva interdisciplinar, en la línea de lo que abogaba la escuela historiográfica de Annales, en boga en esos años. Se interesó también por la situación de la mujer y lo que supuso de retroceso el Franquismo, en relación con lo conseguido durante la República. En este sentido, una de sus líneas de investigación se ha centrado en diferentes aspectos de la educación y promoción social de la mujer en los años de 1939 a 1975. Tuvo la oportunidad de conocer a Pilar Primo de Rivera y a otras mujeres, delegadas nacionales de la Sección Femenina, a las que pudo entrevistar.

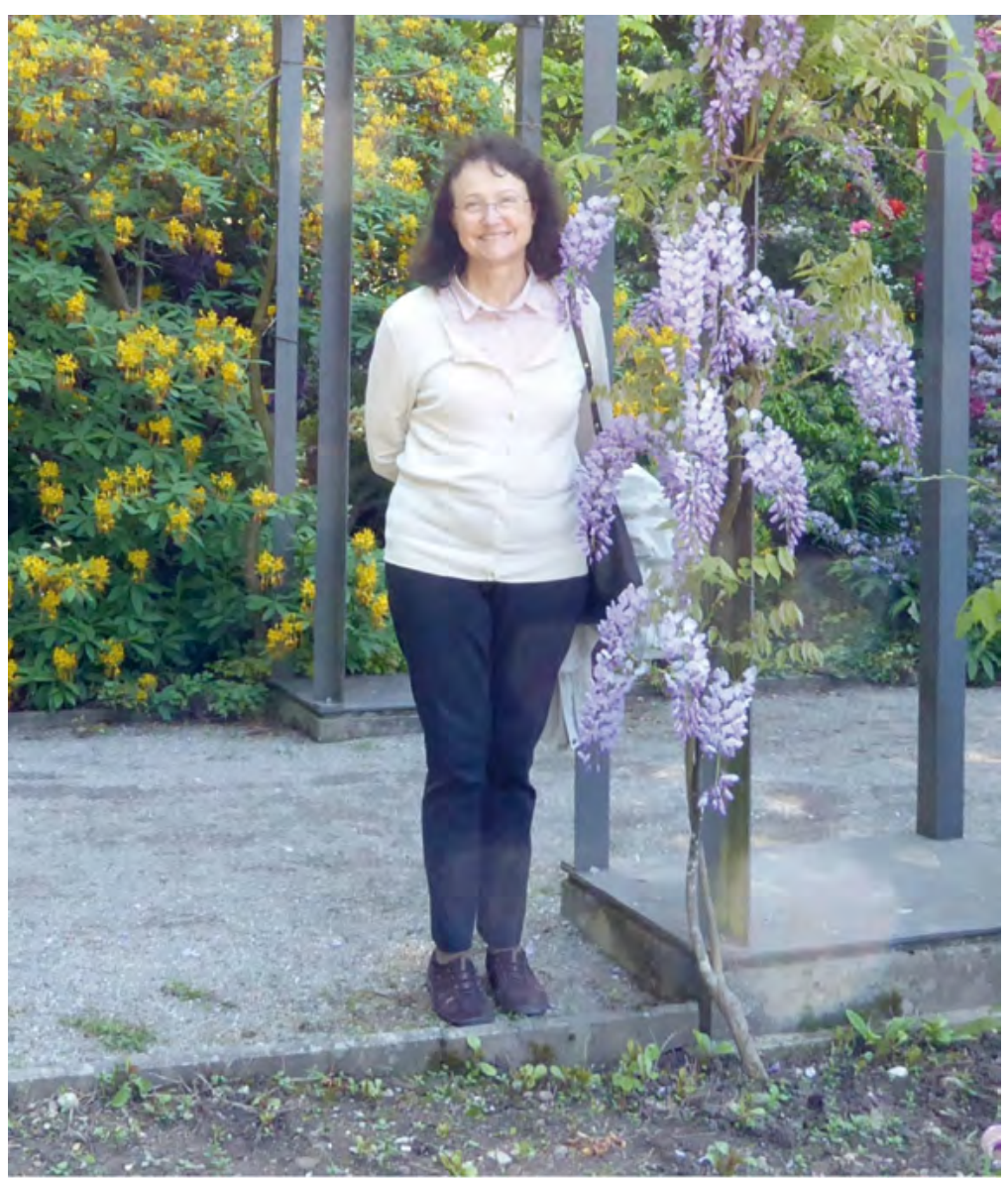

Alicia Alted, 2018 
Tus tesis de licenciatura y doctorado trataron sobre la figura de Pedro Sainz Rodríguez, quien fuera primer Ministro de Educación del régimen de Franco, ya en el gobierno de Burgos. ¿Cómo llegaste al estudio de este personaje?

En mi casa nunca se había hablado sobre la guerra civil, y por supuesto nunca se hablaba del exilio ni de política. Como la guerra civil es algo que afectó a todas las familias y estuvieron implicadas personas de los dos bandos contendientes, entonces te explicas esos silencios. Luego, de mayores, mis padres sí nos contaron a mi hermano y a mí las diferentes versiones de la guerra, pero cuando ya teníamos una madurez que nos permitió comprender el porqué de determinadas actuaciones de miembros de las diferentes familias.

Por otra parte, en las asignaturas de la carrera nunca llegamos hasta la guerra civil y tampoco habíamos estudiado el franquismo, que se sentía como una etapa muy cercana. Eran los años finales de la dictadura, terminé la licenciatura en junio de 1975, todavía estaba Franco vivo. Sentía un gran interés por el tema de la guerra y por ese periodo de la historia. Además, en la Universidad del 70 al 75 fueron años muy convulsos, siempre había asambleas, había mucha efervescencia estudiantil y cultural de todo tipo. Entonces uno mismo se preguntaba el porqué de esas situaciones, y es lo que me llevó a interesarme por esa parte de la historia de España que nos afectaba de una manera muy directa y cercana.

Tuve una oportunidad muy buena para ello cuando entré en contacto con el departamento de Bibliografía de la Facultad de Filosofía y Letras de la Universidad Complutense, que dirigía entonces el profesor Simón Díaz, que era también director del Instituto de Estudios Madrileños en esos momentos. Me ofrecieron la posibilidad de hacer una tesis de licenciatura sobre Pedro Sainz Rodríguez, un personaje que había sido catedrático de Bibliografía en los años 30 en la entonces Universidad Central. En el departamento se estaban haciendo unos esbozos biográficos de los distintos catedráticos que habían pasado por allí. Pero este personaje tenía una relevancia política, no era simplemente un bibliógrafo o un erudito, sino que a la vez había tenido una presencia en la vida pública española reciente, había sido el primer Ministro de Educación en el Gobierno de Burgos y luego también tuvo relación con Don Juan y había tenido un papel preponderante en el exilio monárquico. Tenía una faceta política, 
y por eso pensaron que un historiador o una historiadora era la persona idónea para hacer una bio-bibliografía de Pedro Sainz Rodríguez. En esos momentos estaba dando clase en formación profesional, pero tenía claro que mi objetivo era la universidad, que me gustaba mucho la investigación, y agradecí que confiaran en mí para hacer esa biografía.

Me pusieron en contacto con Pedro Sainz Rodríguez con el fin de que pudiera tener más facilidad para consultar la documentación que precisara. Esa documentación estaba una parte en su domicilio particular y otra en la Fundación Universitaria Española, de la que él era uno de los socios fundadores y en la que estaba como patrono. Fue en 1977 cuando me citó en su casa del Parque de las Avenidas. Recuerdo que me recibió, como luego me recibiría siempre, con un batín, no sé si era de terciopelo. Era una persona que tenía una gran presencia, muy bajito, muy grueso, muy simpático. Verdaderamente me quedé muy asombrada, porque yo tenía 24 años y no pensaba que él tendría mucha confianza en mis capacidades. Sin embargo, cuando me vio lo primero que hizo fue acogerme con una gran simpatía. Me enseñó la inmensa biblioteca que tenía en su casa, llena también de ficheros y de papeles, y me ofreció la posibilidad de trabajar allí libremente. El que una persona con esa trayectoria y con esa formación me diera de entrada esa confianza fue algo verdaderamente asombroso, y pensé que tenía que aprovechar esa circunstancia. Entonces empecé a ir a su casa; él estaba trabajando en su despacho y en la parte de la derecha había puesto una mesa pequeñita para mí. Empecé a trabajar allí y también en la Fundación, donde estaba la otra parte de sus fondos. Charlábamos, era un personaje muy cercano, me contaba muchas anécdotas; yo le preguntaba cuando tenía dudas con los papeles, cuando había algo que no entendía. Aparte de esa relación de afectividad profesional, empecé a entender muchas cosas que de otra manera no hubiera podido conocer.

Aunque con el profesor José María Jover me había formado en una determinada línea en la Facultad, debo reconocer que Sainz Rodríguez también contribuyó a mi formación en cuanto a la erudición, en cuanto a la necesidad de indagar hasta el fondo de las cosas. Él era tremendamente erudito, un bibliógrafo y un bibliófilo a la vez. Ese rigor en cuanto a las referencias, en cuanto a la necesidad de buscar el porqué de las cosas, todo eso me lo fue transmitiendo. Fue una persona que contribuyó enormemente a mi formación profesional como investigadora, y es una cosa que tengo que agradecerle. 
No quiero dejar de mencionar que don Pedro tenía entonces una gran amistad de años atrás con Consuelo Gil Roësset, quien en esos momentos le ayudaba mucho actuando un poco como su secretaria. Consuelo Gil era una señora con un gran encanto y había tenido una trayectoria interesante, había sido editora de publicaciones femeninas, entre ellas de la revista Chicas. Tenía en su casa de la Plaza del Cordón de Madrid una parte del archivo de Pedro Sainz Rodríguez, y también a mí me ayudaba mucho. En su casa había carpetas y más carpetas donde se conservaba el inmenso y riquísimo epistolario de Sainz Rodríguez. Les traté mucho a los dos y conservo un recuerdo muy grato de ambos.

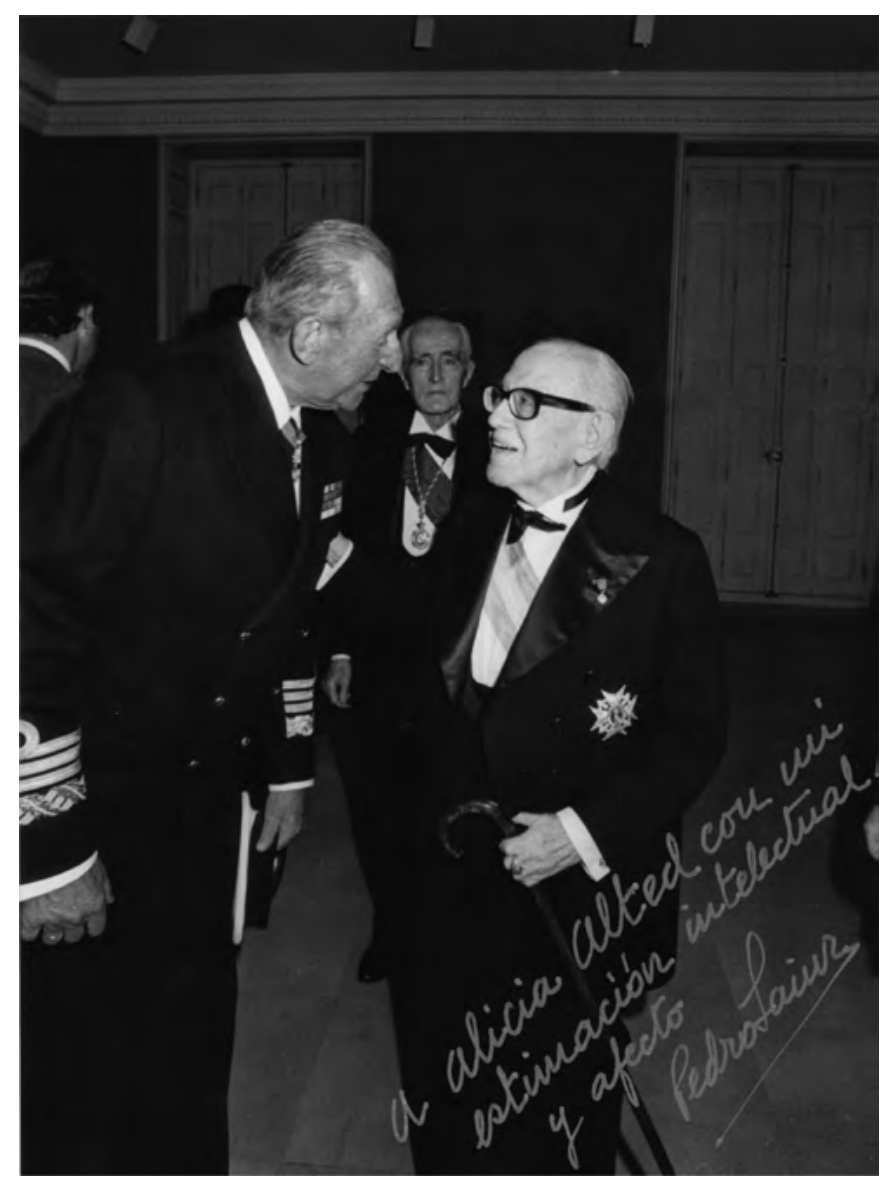

Fotografía dedicada por Pedro Sainz Rodríguez a Alicia Alted, con motivo de la defensa de su tesis doctoral, 1983 


\section{Cuéntanos algo más sobre la figura y la trayectoria de Sainz. Rodríguez}

La figura de don Pedro es una figura muy controvertida y, como tantos personajes de la Historia, poco conocida y que merecería tener una mayor presencia. Es una figura muy poliédrica, un personaje que siempre fue coherente consigo mismo y con sus propias ideas. En un momento determinado, por las circunstancias históricas de la España de los años 30 y la Europa de entreguerras, sufrió un proceso de radicalización, pero luego volvió otra vez a sus ideas, a su conservadurismo tradicional, católico, pero de corte bastante liberal, y no es una contradicción, aunque pueda parecerlo. Era un personaje al que por su formación y por sus antecedentes familiares se le podría encuadrar dentro de una derecha conservadora y profundamente católica. En los años 20 y 30 se codeó con toda la intelectualidad de las que llamamos generación del 98 y generación del 14; tenía relaciones y amistades con personajes con los que realmente se llevaba muy bien. Ya empezó a tener una relevancia política durante la dictadura de Primo de Rivera cuando contestó la política educativa que trataba de sacar adelante Eduardo Callejo, y luego tuvo también una importante participación en los aspectos no solo intelectuales sino también educativos del segundo bienio republicano a través de su amigo Filiberto Villalobos.

En los años de la República, Pedro Sainz Rodríguez se alió al grupo de intelectuales de Acción Española, que estaba muy en contacto con L'Action Française de Charles Maurras. También en un momento determinado tuvo contactos con la Italia de Mussolini, en los años 34 y 35, y estaba claramente posicionado, como otros intelectuales se habían posicionado en otras posturas políticas. Cuando se produjo el alzamiento obviamente Sainz Rodríguez tenía claro del lado del que estaba. Era muy amigo de Pemán y colaboró con él cuando este fue nombrado presidente de la Comisión de Cultura y Enseñanza de la Junta Técnica del Estado. Sainz Rodríguez tenía muy buenas relaciones con el Vaticano y esa componente católica tan fuerte suya fue uno de los factores fundamentales para que se le nombrara ministro de Educación Nacional en el primer gobierno de Burgos. Cuando estaba trabajando en la tesis de licenciatura me di cuenta de la importancia que tenía su labor como ministro y me di cuenta también de que eso no estaba estudiado. Entonces decidí que en la tesis doctoral quería estudiar esa etapa, con esa documentación y con otra que había en la sección de educación del Archivo General de la Administración. 
Lo que es cierto es que Pedro Sainz Rodríguez era fiel a sus principios. Pensaba que Franco iba a restaurar la monarquía de Don Juan; era bastante contrario a los alemanes y no le gustaba para nada la forma de actuar de los falangistas. Él más bien estaba muy vinculado a Gentile y a todo el grupo de intelectuales italianos, así como a la derecha conservadora francesa. Cuando terminó la guerra fue depuesto de forma fulminante en abril de 1939 por sus pretensiones monárquicas, y desde esa fecha hasta 1942 estuvo conspirando con el grupo de militares y de monárquicos que estaban en el interior. Con la conspiración del 42 algunos de ellos fueron a la cárcel y otros se exiliaron. Sainz Rodríguez se exilió a Portugal y estableció su residencia en Estoril hasta el año 1969, en que regresó otra vez a España. Formó parte del consejo privado de Don Juan y tuvo una activa participación política en muchas de las gestiones que se llevaron a cabo desde Estoril y en los contactos de los monárquicos con los socialistas. Pedro Sainz Rodríguez movió muchos hilos en el exilio, es una faceta que quizás tendría que estudiarse más. Yo no la pude trabajar en profundidad, quedarían muchas cosas todavía por conocer. Luego ya regresó a España y podemos decir que otra vez volvió a su propio ser, ese liberal conservador que se codeaba con personas de distinto signo y monárquico hasta la médula toda su vida, profundamente católico, con esas contradicciones que tiene el sentir católico español. Estaba vinculado muy estrechamente a la Fundación Universitaria Española y continuó con su labor de erudición y de escritura.

Realmente es un personaje que merece la pena conocerse, porque, aunque tuvo ese momento en que apoyó claramente a la dictadura, tenía sin embargo un poso liberal. Hay cartas en su inmensa e ingente correspondencia que nos evidencian cómo durante la guerra era consciente de las tropelías que se estaban cometiendo, y que de alguna forma había que parar. Una guerra civil hace que aflore lo más terrible del ser humano, pero eso no debería haber pasado. Entonces es un personaje con luces y con sombras, y hay que valorarlo así; hay que tratar de ver toda la trayectoria de un personaje y no sólo un determinado momento de su vida, y entonces se le puede entender.

A principios de los años ochenta estabas como becaria de la Fundación Universitaria Española, de la que era patrono y director cultural Pedro Sainz Rodríguez. En aquellos años se depositó allí el archivo del gobierno de la República española en el exilio y tuviste ocasión de formar 
parte de un equipo de investigadores que se dedicó a inventariar y estudiar ese material. ¿Cómo llegó ese archivo a esa institución?

En marzo de 1977 habían cancelado sus relaciones diplomáticas con el Gobierno de la República española en el exilio los dos únicos países que mantenían ese reconocimiento desde 1945: México y Yugoslavia. En esos momentos los papeles del archivo se encontraban en muy malas condiciones y repartidos en la última sede del gobierno en Boulogne-Billancourt, cerca de París, y en los sótanos de la embajada de Yugoslavia en París. Cuando se cancelaron las relaciones con este país, un refugiado español ofreció la planta alta de su casa en Mont-Morençy para guardar de manera provisional esa parte de la documentación. Ante esta situación fue esencial la actuación de José Antonio Ferrer Benimeli, especialista en la masonería y que tenía muy buena relación con los últimos presidentes de la República y del Gobierno en el exilio, José Maldonado y Fernando Valera. Ferrer Benimeli ofreció a Valera la posibilidad de trasladar todo el Archivo a la Fundación Universitaria Española. El acuerdo se firmó en París en enero de 1978, entre Pedro Sainz Rodríguez y José Maldonado.

En el momento en el que se firmó el documento los papeles del archivo se encontraban en una situación crítica. Tras las elecciones de junio de 1977, a las que no pudieron concurrir los partidos republicanos porque no habían sido legalizados, Maldonado y Valera habían decidido poner fin a la legitimidad institucional que habían encarnado las instituciones republicanas reconstituidas en México en agosto de 1945. Esto agravó el problema de qué hacer con los papeles. Ambos tenían algo claro, y era que no querían que volvieran a una institución estatal española porque el gobierno español de la época no había querido reconocer a los partidos republicanos, como ya he dicho. Pero tampoco tenían ninguna institución en ese momento que pudiera acoger esos papeles y se iban a perder. Entonces es cuando, gracias a esas gestiones de Ferrer Benimeli, se llegó al acuerdo. Resulta curioso que el archivo acabara en una Fundación creada en 1949 como entidad benéfico-docente, con una clara orientación monárquica y conservadora. Realmente las personas son las que van dando su impronta a las instituciones y eso nos ayuda a entender por qué se pudieron poner de acuerdo políticos e intelectuales de orientación ideológica muy diversa, pero de gran valía personal y muy liberales al margen de sus creencias. 
En lo que a mí respecta, había entrado a trabajar en la Fundación como becaria en 1976 para desarrollar tareas de catalogación bibliográfica vinculadas al Seminario Menéndez Pelayo que dirigía el profesor José Simón Díaz. Había colaborado en la elaboración de unos Índices de la obra de Bartolomé José Gallardo Ensayo de una biblioteca española de libros raros y curiosos, y cuando llegó el archivo de la República estaba terminando la clasificación y organización del archivo del jesuita Félix González Olmedo.

Cuando llegó el archivo manifesté mi deseo de entrar en el equipo de catalogación del mismo. Integraba el archivo la documentación generada por la gestión del Gobierno desde su traslado a París a principios de 1946 hasta la disolución de las instituciones en 1977. A estos papeles que constituían el llamado fondo París, se le agregaron otros dos fondos procedentes de Chile y de México. La documentación llegó a la Fundación entre 1979 y 1980. En 1981 se formó el equipo de trabajo para empezar su catalogación gracias a una ayuda recibida del Comité Conjunto Hispano-Norteamericano para Asuntos Educativos y Culturales. Estuvimos durante tres años catalogando una parte del fondo México y el fondo Chile. Pero claro, el grueso de la documentación lo constituía el fondo París, que eran 1.046 cajas. La documentación había llegado en sacos, literalmente en sacos, y lo primero que hubo que hacer fue coger los papeles y meterlos en cajas. Conforme cogíamos un bloque de papeles lo metíamos en una caja; la documentación estaba totalmente desordenada, desorganizada. El equipo estuvo catalogando hasta 1983.

Al terminarse la ayuda financiera y dispersarse varios miembros del equipo, me quedé sola y durante diez años trabajé en el inventariado del fondo París, que recogí luego en un libro que publicó la Fundación; en la introducción explico todo el proceso de cómo llegó el archivo allí y curiosamente el prólogo me lo escribió Juan Marichal. Cuando fui a pedir a Marichal que me escribiera el prólogo, me dijo: «Sí, pero Usted explíqueme cómo se pudieron poner de acuerdo y cómo llegó el archivo a la Fundación». Entonces le pedí que leyera la introducción porque estaba segura que cuando conociera las circunstancias, lo iba a entender. Fue muy amable. Y no quiero olvidarme de una gran archivera y luego amiga, Vicenta Cortés, que me ayudó mucho en el proceso de inventariado. 
Afortunadamente, y al margen de temas ideológicos, en la Fundación acogieron el archivo, se ha podido introducir dentro del sistema de PARES ${ }^{1}$, se conserva y ha estado allí desde entonces a disposición de los investigadores. Claro, la Fundación era una institución monárquica y al principio el archivo de la República resultaba para algunos patronos algo incómodo: "Vaya cosa que nos legó Pedro Sainz Rodríguez». Pero no dejaba de ser un archivo, y había habido un acuerdo legal entre tres hombres públicos de hondas convicciones: en un caso monárquico alfonsino, luego juanista, conservador y profundamente católico; en el otro, dos republicanos laicos, liberales y, en lo que respecta a Valera, eminente masón. Todo un ejemplo para la Historia.

Este trabajo de catalogación del fondo París lo hiciste cuándo ya habías terminado la tesis doctoral. ¿Fue este el inicio de tu interés por el estudio de la guerra civil española y el exilio?

La tesis la defendí en 1983, pero dos años antes, en 1981, la Fundación me había publicado mi primer libro, La revista "Filosofía y Letras», en el que no sólo me ceñía al estudio de esa publicación, en la que había participado Sainz Rodríguez, sino que también, al hilo de la misma, estudié la vida universitaria de las primeras décadas del siglo xx, en particular en la Facultad de Filosofía y Letras de la Universidad de Madrid. Disfruté mucho escribiéndolo, dediqué un capítulo a la participación femenina en la revista que me sirvió para acercarme a la figura de Emilia Pardo Bazán, e incluí un capítulo final en el que entrevistaba a tres de sus colaboradores: el propio Sainz Rodríguez, Luis Morales Oliver y Florencio Porpeta Clérigo.

En 1982 me incorporé como profesora ayudante al departamento de Historia Contemporánea de la UNED. En la Fundación continué inventariando el fondo París del archivo de la República y fue a partir de esos años cuando empecé a tomar contacto con republicanos históricos y cuando comencé a meterme de lleno en el tema del exilio. Como siempre pasa, conforme más ahondaba, más facetas nuevas descubría. Es cuando empecé a estudiarlo de forma seria.

\footnotetext{
${ }^{1}$ PARES es el Portal de Archivos Españoles, del Ministerio de Cultura, accesible en http://pares. mcu.es/
} 
El primer republicano al que entrevisté fue el último presidente del gobierno de la República en el exilio, José Maldonado. En marzo de 1984 me desplacé a Oviedo en una primera toma de contacto y en mayo fui para hacerle una larga entrevista que se publicó en los Cuadernos Republicanos del CIERE, institución con la que había empezado a colaborar. ${ }^{2}$ Maldonado era un hombre muy de orden, tremendamente cortés y amable, en la línea de una burguesía de clase media, liberal, no creyente, pero muy respetuoso con los «convencionalismos» (como decía) religiosos... Otra buena experiencia; siempre he procurado enriquecerme y aprender de todo lo que las personas han podido transmitirme, sin olvidar mi función como historiadora, claro.

Después conocí y entrevisté a otros republicanos. En 1987 tomé contacto con Andrés Cecilio Márquez, miembro de la Comisión Ejecutiva Nacional de ARDE. ${ }^{3}$ Con él y su mujer mantuve una buena amistad y me introdujo en la tertulia que compartía con otros republicanos que habían vivido en el «exilio interior». Me transmitieron su modo de pensar y de sentir y me ayudaron mucho en mis trabajos. No puedo olvidarme de una bellísima persona, Virgilio Botella Pastor, hijo del que fuera ministro de Justicia durante dos escasos meses en 1933, Juan Botella Asensi. Conocí personalmente a Virgilio Botella y a su mujer, Dolores Fernández, en su domicilio en Gijón en octubre de 1996. Me acogieron en su casa, pasé con ellos un largo fin de semana, entrevisté a Virgilio Botella y cuando me despedí, me entregó un manuscrito inédito con el ruego de que intentara publicarlo. Eran sus Entre memorias. Las finanzas del Gobierno Republicano español en el exilio. Cuando le conocí, estaba ya enfermo y murió tres meses después. Tras muchos avatares, conseguí que se publicaran sus Entre Memorias en 2002 gracias al apoyo de un especialista del exilio literario y amigo como es Manuel Aznar Soler.

En definitiva, fue la llegada del archivo a la Fundación Universitaria Española lo que hizo que empezara a adentrarme en el tema del exilio, primero a través del republicanismo histórico. Luego ya vi que el exilio

\footnotetext{
${ }^{2}$ CIERE: Centro de Investigación y Estudios Republicanos, http://www.ciere.org/

${ }^{3}$ Acción Republicana Democrática Española (ARDE), fue un partido político creado en el exilio, resultado de la fusión de los dos partidos republicanos históricos, Unión Republicana e Izquierda Republicana.
} 
era mucho más que eso; los republicanos y las instituciones republicanas eran una parte de la historia del exilio. Empecé a hacerme preguntas sobre quiénes eran los exiliados, por qué habían tenido que ir a los diferentes países, de qué manera habían ido. Entonces fui ampliando el espectro de mis intereses sobre el tema.

En el año 1988 coordinaste junto con el profesor Javier Tusell un importante congreso internacional sobre "La oposición al régimen de Franco", que se celebró en la UNED y que tuvo una amplia resonancia en aquellos años. Esta fue seguramente una ocasión para que tomaras contacto con los investigadores que en Francia se interesaban por el exilio republicano español y para establecer contactos con exilados españoles en el país vecino. Cuéntanos un poco de todas esas experiencias.

En esos años seguía con el inventariado del archivo y hablaba de vez en cuando con Javier Tusell de los avances en mis investigaciones sobre el exilio y de los contactos que estaba teniendo con exiliados. En un momento dado me comentó que debíamos organizar un gran congreso internacional sobre la oposición al franquismo, tanto en el exilio como en el interior. El congreso tuvo lugar en octubre de 1988 y creo que tuvo un carácter pionero muy importante, que luego abriría la puerta a otros congresos académicos sobre la oposición interior y el exilio. Se acompañó de actividades culturales, entre ellas una muy buena exposición, y tuvo una amplísima representación de historiadores y de protagonistas, con una verdadera vertiente internacional. Vinieron muchos hispanistas que estaban trabajando no solo el tema de la oposición al franquismo, sino también aspectos de la Transición que ya se estaba empezando a trabajar.

Para mí fue toda una experiencia que me permitió tomar contacto con personas de la oposición interior y del exilio con los que luego trabajé, así como con historiadores ya consagrados o con jóvenes historiadores que empezaban a investigar sobre estos temas. En una misma mesa tuvimos a Manuel Tuñón de Lara y a Jorge Semprún y coincidí con José Luis Abellán, Juan José Linz, Santos Juliá, Elena Hernández Sandoica, Giuliana Di Febo, María Fernanda Mancebo, Anna Caballé, Maryse Bertrand de Muñoz, Jordi Planes, Carlos y José Martínez Cobo, Francisco Giral, Manuel Andujar... La lista de participantes es amplísima, remito a los tres gruesos volúmenes de actas que se publicaron. 

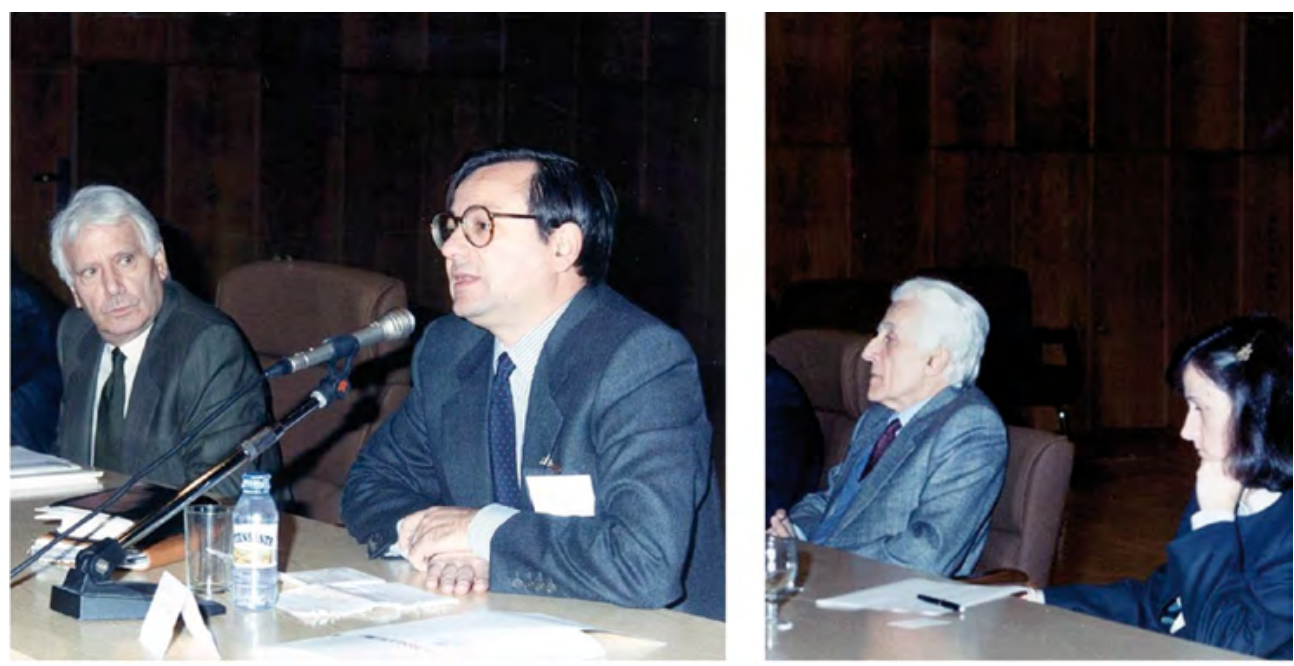

Congreso Internacional sobre La oposición al régimen de Franco, organizado por el departamento de Historia Contemporánea de la UNED, Madrid, octubre de 1988.

De izquierda a derecha, Jorge Semprún, Javier Tusell, Manuel Tuñón de Lara y Alicia Alted.

Estos macrocongresos dan mucho trabajo, pero merecían la pena. Volví a caer en la tentación de dirigir la organización de este tipo de jornadas en dos ocasiones más. En 1999, con ocasión del sesenta aniversario del inicio del exilio de 1939, coordiné, en el marco de la convocatoria de Congreso Plural que hizo Manuel Aznar y su Grupo de Estudios del Exilio Literario (GEXEL), un congreso sobre La cultura del exilio republicano español de 1939, que se celebró en la UNED en Madrid, la Universidad de Alcalá y la Universidad de Castilla La Mancha en Toledo. El cartel anunciador del congreso era una reproducción de un guache sobre cartón que nos pintó ex profeso Eugenio F. Granell y que su autor donó a la Universidad de Castilla La Mancha, donde confío se conserve.

La segunda ocasión fue en 2009 con motivo del setenta aniversario del inicio del exilio, cuando asumí la dirección de una serie de actos que organizó la UNED con la Sociedad Estatal de Conmemoraciones Culturales. Colaboraron muchas instituciones y personas y organizamos actividades múltiples en París y varios lugares del sur de Francia, Ginebra, Buenos Aires y Rosario, Montevideo y México. Fue una experiencia fantástica por las personas que participaron y por todo lo que hicimos. 
Recuerdo un recital de música de Amancio Prada en el Anfiteatro Richelieu de La Sorbona sobre Poemas del Exilio y la Distancia, una ruta del exilio que me llevó al descubrimiento de la maternidad de Elna, la mesa redonda con niños de la guerra que se celebró en el Palacio de la Legislatura de Buenos Aires... Fue todo un lujo, de verdad, y la gente se volcó, pero también resultó agotador.

Volviendo al congreso de 1988, considero que fue muy relevante tanto desde el punto de vista de los historiadores como de los testigos que habían vivido esos acontecimientos de la guerra y del exilio. En esos años ochenta todavía quedaban vivas muchas personas de primera generación que habían vivido la guerra y las primeras décadas de oposición interior y de exilio. Además, era de las primeras veces que se confrontaban las opiniones de los testigos y su propia vivencia personal de los hechos que habían protagonizado o habían vivido, con el estudio y los análisis de los historiadores. Luego esto se haría en todos los grandes congresos sobre la oposición en el interior y en el exilio, pero pienso que este fue el primer gran congreso en donde protagonistas e historiadores confrontaron sus vivencias y análisis sobre la realidad de lo que se estaba hablando.

Al congreso vinieron algunos profesores que estaban trabajando el exilio en Francia y entablé contacto con una persona que ejercería una gran influencia en mí como fue Lucienne Domergue. Era una hispanista que vivía en Toulouse, una gran estudiosa del siglo XvIII español, pero a la vez había tomado contacto en los años cincuenta, cuando estaba estudiando la carrera, con los anarquistas que vivían en Toulouse y su región. Entonces se había sentido muy atraída por todo lo que hacían, por la historia de esos anarquistas que vivían allí, también de los socialistas. Ambos colectivos tenían una fuerte presencia en Toulouse, menos numeroso era el comunista, y los republicanos tenían una presencia testimonial. Lucienne empezó a recoger ya en los años setenta testimonios y documentación de los anarquistas y se convirtió en la, a mi juicio, mejor especialista sobre las manifestaciones culturales de los anarcosindicalistas en el sur de Francia.

Tres años después, en 1991, se celebraron tres congresos en Salamanca, París y Turín sobre migración y exilio de españoles e italianos en Francia entre 1936 y 1946. Esto me permitió afianzar las relaciones con historiadores franceses que llevaban trabajando desde hacía años estos temas, en 
particular con el grupo de Toulouse. Y fue con Lucienne Domergue, Jean Pierre Amalric, Pierre Laborie y Antonio Risco con quienes diseñé un proyecto para la realización de un documental sobre lo exiliados españoles en el Mediodía de Francia. La producción del documental nos permitió recoger un estupendo banco de documentos visuales, gráficos y testimonios. Filmamos lugares que ya no existen, como la sede del Partido Socialista y donde se reunían los socialistas en la rue Belfort de Toulouse. Por ejemplo, el librero Antonio Soriano nos acompañó para enseñarnos los distintos lugares de memoria de Toulouse, lo fuimos grabando y luego le entrevistamos en el famoso Hotel du Balcon donde se alojó Saint-Exupéry.

El documental se editó por la UNED en dos partes en 1996, y el libro en 1999. En ambos se recogía la presencia de los exiliados españoles en Toulouse y su región. En 2003 hicimos una traducción al español editada por la UNED y la Universidad de Toulouse. A raíz de entonces, Lucienne y yo pensamos en escribir un libro que recogiera la riqueza de las manifestaciones culturales y artísticas de los anarcosindicalistas en el sur de Francia. Empezamos a trabajar en el mismo y por diversos motivos se fue retrasando. En 2007 Lucienne falleció de manera repentina, su parte la tenía casi terminada, continué trabajando y en esta tarea me ayudaron mucho los amigos anarquistas de Toulouse. Se editó en 2012.

Tus investigaciones se han basado en buena parte en testimonios orales, lo cual te ha hecho profundizar en las cuestiones metodológicas que afectan al trabajo con este tipo de fuentes ¿Podrías ampliarnos un poco tu experiencia en este campo, y su importancia en particular para el estudio del exilio republicano?

Como ya señalé, en este campo me formé con Carmen García Nieto; me considero discípula de ella, establecimos una amistad muy entrañable hasta que falleció. Prácticamente desde 1977 empecé a hacer entrevistas orales. Mi primer libro sobre la Revista de Filosofía y Letras ya incluyó una parte de entrevista oral, e hice una larga entrevista a Pedro Sainz Rodríguez que reproduje en la tesis doctoral. Pero cuando empecé con el tema del exilio es cuando realmente vi la necesidad de recoger testimonios orales, porque había muchísimos aspectos para los cuales la fuente oral resultaba muy importante, en gran medida porque había documentación que estaba inaccesible, se había perdido, o bien estaba incompleta, como siempre pasa. 


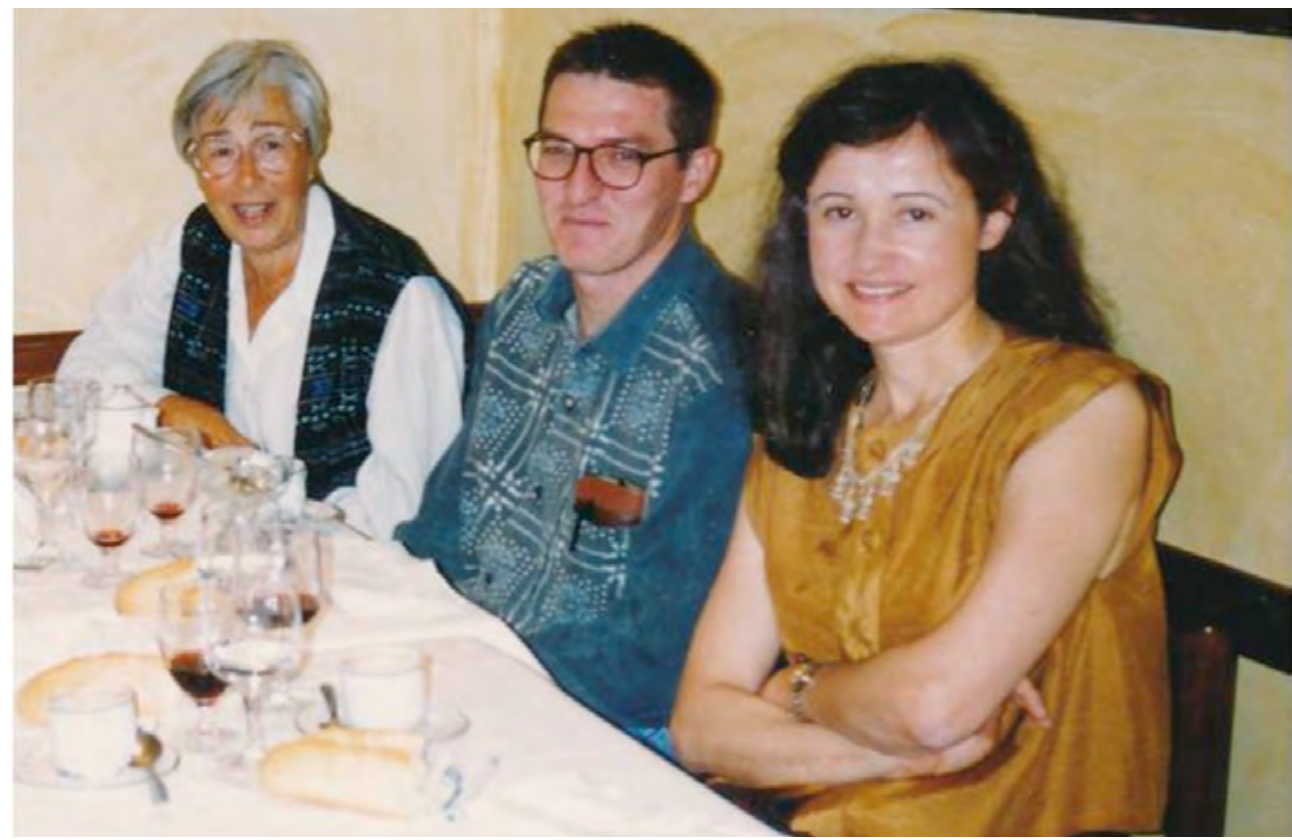

Reunión del Seminario de Fuentes Orales dirigido por Carmen García Nieto, en la que aparecen Carmen García Nieto (a la izquierda de la imagen) y Alicia Alted (a la derecha de la imagen). Junio de 1995.

La fuente oral la utilicé muchísimo para todos los estudios que luego publiqué sobre los republicanos del interior, para perfilar mejor cómo veían los propios republicanos la reconstitución de las instituciones de la República en el exilio. Desde ahí me fui a trabajar con el colectivo de los exiliados en Francia para hacer los documentales, y fui ampliando más el marco. En Francia había que recoger las experiencias de los anarquistas y de los socialistas, y trabajamos muchísimo con la fuente oral. Casi siempre solía alojarme en casa de los propios exiliados o de amigos hispanistas y esto suponía un enriquecimiento complementario. Recuerdo cuando estuve en casa de la anarquista Pepita Carpena en Marsella y dormía en la habitación donde tenían la biblioteca, una maravilla. O también cuando tomé en casa de Dolores Marín en Toulouse una estupenda tortilla de patata; fui con María Batet, amiga y secretaria de Federica Montseny, y desde allí llamamos a Federica que estaba en una residencia y pude hablar con ella por teléfono. Para una historiadora esto es algo verdaderamente importante. 


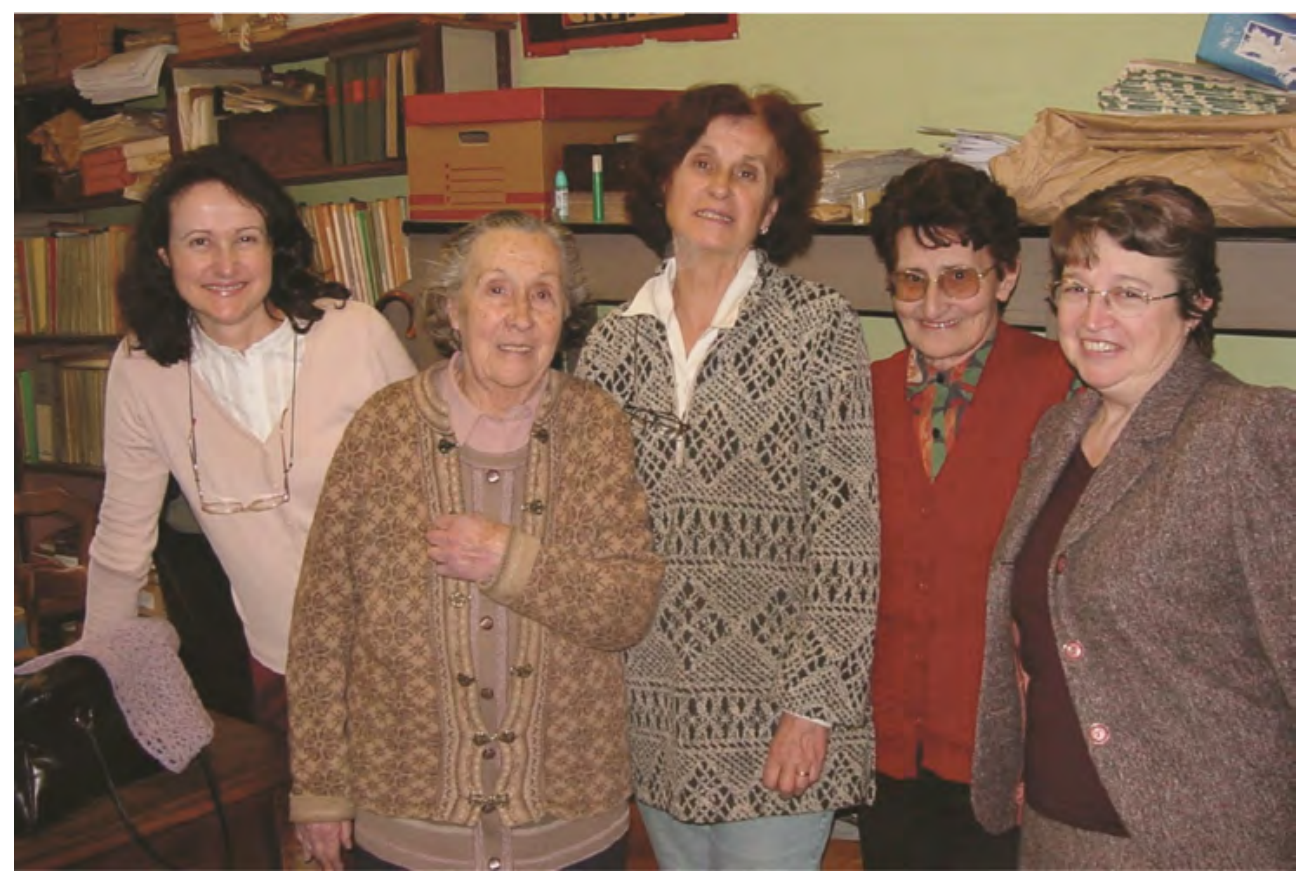

En la sede de los exiliados anarquistas en la rue Belfort de Toulouse. De izquierda a derecha, Alicia Alted, María Batet, Lucienne Domerge, Gladis Samitier y Placer Thibon, 1999 (?).

En México era otro tipo de exilio; por ejemplo, tuve la ocasión de conocer a Manuel Andújar, hice un trabajo sobre la revista Las Españas que él junto con otros exiliados dirigió. Le hice una larguísima entrevista y le visité en su casa. También tuve una buena amistad con Conchita Ruiz-Funes; me hablaba siempre del importante papel desempeñado por las mujeres para facilitar los procesos de integración. En mis constantes búsquedas seguí ampliando el marco geográfico para una comprensión mejor de todo lo que fue el exilio; no quería centrarme en el exilio en Francia, el exilio en México, el exilio en Cuba o el exilio en el Norte de África, sino que quería tener la visión de conjunto del exilio. Y eso es lo que traté de hacer cuando la editorial Aguilar me lo pidió, en el libro La voz de los vencidos que se publicó en el 2005. 


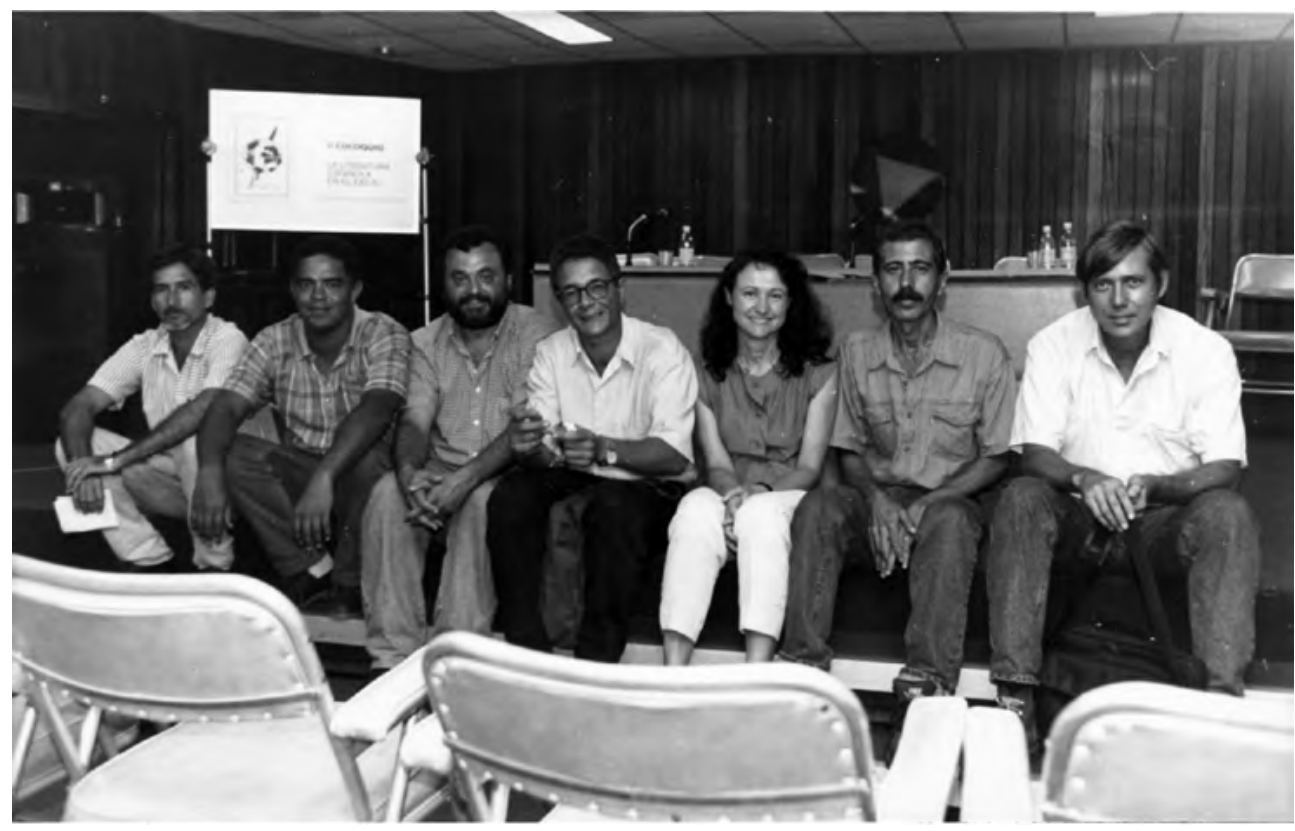

II Simposio Internacional de la Cultura y la Literatura Española en el Exilio, La Habana, 1998.

De izquierda a derecha, Rafael Medina (escritor), Miguel Terry Valdespina (periodista), Manuel Aznar Soler (catedrático de Filología Hispánica de la UAB), Omar Felipe Mauri (representante de la Unión de Escritores y Artistas de Cuba), Alicia Alted Vigil; Roger González Martell (historiador e investigador literario de la Casa del Escritor Habanero de San Antonio de los Baños), Jorge Domingo Cuadrillero (investigador del Instituto de Literatura y Lingüística de La Habana).

Así pues, no sólo me interesaba el marco geográfico de los países de acogida, sino también los diferentes colectivos humanos y políticos, y esto me condujo al colectivo de los niños. Tuve ocasión de empezar a trabajar con ese colectivo en 1995, cuando entré en contacto con la Fundación Francisco Largo Caballero. Empecé a trabajar de una forma muy intensa con el testimonio, como ya lo había hecho antes. Y fue entonces cuando perfilé con más rigor la metodología y las técnicas de recogida del testimonio oral y su utilización como fuente en una investigación.

Para resumir brevemente, creo que el testimonio oral es una fuente básica para el estudio de la historia más reciente, de la llamada Historia del Tiempo Presente. Pero la fuente oral tiene que ser contrastaba porque con ella estamos utilizando la memoria para reactualizar; es algo 
que están creando en un momento determinado el testigo y el historiador, y hay que conocer los mecanismos de funcionamiento de la memoria: cómo se recuerda, cómo se olvida...

Por otra parte, no es lo mismo entrevistar a un dirigente político que ya ha repetido su discurso muchas veces y tiene elaborado lo que quiere decir, que a una persona de a pie que nos suele dibujar un entorno cotidiano que no se recoge en la documentación oficial. Esa historia que los historiadores recogemos, la tenemos que contrastar con otra documentación en la medida de lo posible, o bien la tenemos que contrastar con otras entrevistas para darnos cuenta de si los testimonios coinciden. Creo que no es exagerado considerar que mi recogida de testimonios y mi formación como historiadora que trabaja los testimonios discurrieron de manera paralela a la consolidación en nuestro país del testimonio oral como fuente y a la consolidación de la llamada historia oral, aunque no me gusta utilizar ese término. A finales de los años setenta no se consideraba para nada en el ámbito de la historiografía la utilización de los testimonios orales, incluso a los historiadores que trabajábamos con ellos se nos cuestionaba. Hoy en día la utilización del testimonio oral como fuente para la investigación es algo que está consolidado y que nadie discute. Todo ese proceso lo he ido viviendo a lo largo de mi propia trayectoria como investigadora.

Retomando el tema que mencionaste de los niños que fueron evacuados a la Unión Soviética y a México, me gustaría que nos hablaras ahora de los niños que se vieron involucrados en la tragedia de la guerra civil y el exilio, que es otro de los temas de investigación en los que has sido pionera.

Entré en contacto con el tema de los niños exiliados en la Unión Soviética cuando en 1995 desde la Fundación Largo Caballero, que ya sabían de los estudios que estaba llevando a cabo sobre el exilio, me pidieron hacer una exposición sobre el exilio de los niños que habían ido a la Unión Soviética; era una exposición itinerante, pequeñita. Entonces empecé a trabajar en ello. Tenían bastante documentación porque habían ayudado mucho, cuando cayó el muro de Berlín, a los últimos retornados de después del año 1989. Tenían historias de vida y documentación que me ofrecieron y querían que las vivencias de este colectivo se conocieran. Entonces es cuando empecé a trabajar en esa 
exposición, y pensé «esto es muy interesante, me gusta mucho el tema, vamos a intentar publicar un libro». Propuse hacer junto a la exposición el libro, me lo aprobaron y con otros dos investigadores, Encarna Nicolás y Roger González, empezamos a trabajar sobre los niños evacuados a la Unión Soviética, con documentación de archivo y sobre todo con testimonios orales que recogimos en diversos lugares de España, en Moscú y en La Habana. Estuvimos trabajando muy intensamente ese tema desde 1996 a 1999, en que publicamos el libro: Los niños de la guerra de España en la Unión Soviética. De la evacuación al retorno (1937-1999).

A título personal me interesaba mucho el tema de los niños y del impacto en ellos de la guerra civil española, de los conflictos bélicos en general. Pero empecé a interesarme muy especialmente por cómo habían vivido los niños la guerra a raíz de comenzar a entrevistar a los niños evacuados. Ya no eran niños, pero lo que les estábamos pidiendo era que recordaran desde un tiempo presente sus experiencias infantiles.

Después de haber hecho esa exposición y el libro, es cuando la Fundación Largo Caballero me propuso diseñar una gran exposición sobre el exilio de los niños en todos los países a los que fueron solos o con sus familias. La exposición la comisariamos Roger González, María José Millán y yo misma. Fue un proyecto francamente bonito en el que estuvimos trabajando bastante tiempo; recabamos documentación de archivos de varios países europeos y americanos y, como en otras ocasiones, colaboramos estrechamente con niños de la guerra que nos dieron sus testimonios y nos prestaron documentos personales para la exposición. Se inauguró en diciembre de 2003 en el Palacio Euskalduna de Bilbao y, tras varias itinerancias, se clausuró dos años después, en junio de 2005, en el Círculo de Bellas Artes de Madrid. Fue una exposición muy amplia y completa sobre el exilio de los niños en los diferentes países, entre ellos México. Abordamos la problemática de los niños de Morelia, con los que también entré en contacto y a algunos de ellos entrevisté. Sobre todo, me impresionó la entrevista que hice a Engracia Cañamares, una niña de Morelia. Pero se dio entonces una circunstancia que me hizo meterme más de lleno en el tema de los niños, y en un aspecto particular inherente a ellos, los dibujos. 
Háblanos entonces ahora de los dibujos que hicieron los niños en las colonias escolares durante la guerra. ¿Cómo llegaste a esos dibujos?

Todo es como un ovillo de lana que se desenreda conforme vamos tirando del mismo. Estábamos trabajando sobre el exilio de los niños y me enteré de que en la Biblioteca Nacional había una colección de dibujos infantiles, que no estaban catalogados y eran inéditos porque se desconocía su existencia por los investigadores. Un día fui a la Sección de Bellas Artes de la Biblioteca y pedí consultar los dibujos. Por esa época había escrito ya algunos textos y estaba impartiendo conferencias sobre la incidencia de los conflictos bélicos en los niños. Estas conferencias las ilustraba con dibujos. Había utilizado documentación que me habían proporcionado en la sede de la UNESCO en Madrid, donde había ido a pedir dibujos de niños en conflictos bélicos actuales, sobre todo de la guerra de Yugoslavia. También había participado en un congreso en Italia sobre Le Guerre dei Bambini.

Estudiando los dibujos de la colección de la Biblioteca Nacional me di cuenta del interés que tenían. La colección se componía de 1.172 dibujos que fueron adquiridos en 1986 a un librero catalán. Era la colección más extensa de las que se tenían noticias de dibujos realizados por los niños en las colonias escolares durante la guerra civil. Las dos colecciones conocidas hasta ese momento y que se encontraban en instituciones públicas, eran los 617 dibujos conservados en la Universidad de California en San Diego, y los 153 de la Universidad de Columbia. El origen de las tres colecciones era el mismo, aunque en el caso de la colección de la Biblioteca Nacional, el librero al que se le compraron los dibujos no dijo por qué tenía en su poder esa importante colección.

Entonces propuse a la Biblioteca un proyecto de catalogación de esos dibujos y de organización de una exposición con una selección de los mismos. Lo aprobaron, y de la catalogación se encargaron Roger González y María José Millán con el asesoramiento y ayuda del personal de la Biblioteca. De manera paralela, los tres íbamos diseñando el proyecto expositivo que se hizo realidad en noviembre de 2006, cuando se inauguró la exposición en la Sala Hipóstila de la Biblioteca con el título A pesar de todo dibujan... La Guerra Civil vista por los niños. 


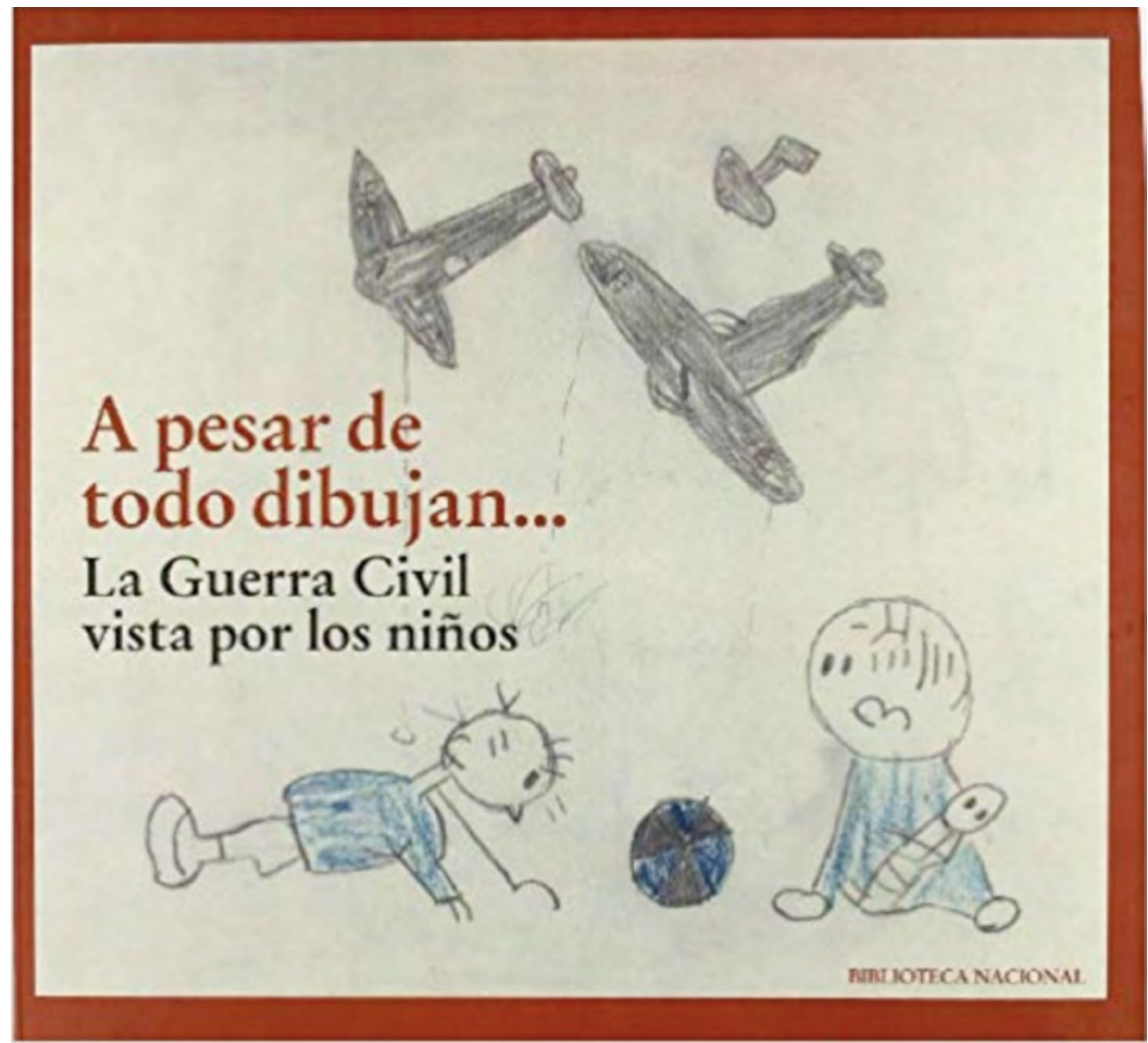

Catálogo de la Exposición A pesar de todo dibujan... La Guerra Civil vista por los niños (portada). Madrid, Biblioteca Nacional, 2006.

A raíz de estudiar ese tema es cuando me apareció una figura muy importante, la de Alfred Brauner, el matrimonio Alfred y Franziska Brauner. Franziska había nacido en Viena y estudió medicina. Alfred había nacido en Francia, pero se había trasladado con su familia a Viena cuando tenía ocho años y se doctoró en Filosofía. Vinieron a España para trabajar con las Brigadas Internacionales, ella como médico y él como encargado de la inspección de los hogares infantiles sostenidos por las Brigadas. A Alfred Brauner le interesaban mucho los dibujos de los niños. 
En los años de la guerra civil se utilizó el dibujo infantil como un elemento para la propaganda. Sabemos que la colección que catalogamos la integraban dibujos que se hacían encargados por miembros del gobierno republicano y por organizaciones de ayuda humanitaria, para luego venderse fuera y recaudar dinero para el sostenimiento de las colonias y de las escuelas. Pero Brauner traía otra mirada: más que su interés por que los niños dibujasen la guerra y la vida en las colonias, lo que quería conocer era cómo los niños podían asumir el trauma de la guerra a través del dibujo. Era la perspectiva de lo que se conocería como Arte-terapia, que luego él iba a trabajar a lo largo de toda su vida.

Cuando terminó la guerra civil, el matrimonio Brauner regresó a Francia llevando en sus maletas fotos de dibujos y copias de redacciones de niños. Durante la Segunda Guerra Mundial se ocuparon de niños judíos. Estas experiencias las recogió Alfred Brauner en un libro publicado en 1946 con el título de Ces enfants ont vécu la guerre. ${ }^{4}$ La mayor parte del material que se llevó el matrimonio Brauner de España se perdió. Con la pequeña parte que se salvó y recuperó de una manera un tanto fortuita, se hizo una exposición en Guadalajara, en paralelo a la de la Biblioteca Nacional, de la que fue comisaria Rose Duroux, hispanista y niña de la guerra, pues atravesó la frontera francesa en febrero de 1939 en brazos de su madre, y con la que me unía una gran amistad.

En la exposición de Guadalajara participé indirectamente. Realmente Rose llevó a cabo una investigación paralela a la que estábamos haciendo en la Biblioteca Nacional. Me di cuenta de que lo de Brauner tenía la entidad suficiente como para trabajarlo por separado; además los dibujos de Brauner no estaban dentro de la colección de la Biblioteca Nacional, era una colección que se conservaba en otro sitio. Pero la figura de Brauner aparecía de manera recurrente al catalogar y estudiar los dibujos de la Biblioteca. Entonces tomamos conciencia de la importancia que había tenido en el ámbito de los dibujos, y es cuando Rose se animó a estudiar el papel del matrimonio durante la guerra y montó una exposición muy interesante. ${ }^{5}$ Después siguió estudiando lo que a lo

\footnotetext{
${ }^{4}$ Editions Sociales Françaises, 1946.

${ }^{5}$ Rose Duroux, Guy Baudon y Luca Gaboardi, Lo que yo he visto de la guerra: los dibujos infantiles de la colección Brauner, 1937-1938 (Guadalajara: Diputación Provincial de Guadalajara, Servicio de Cultura, 2006).
} 


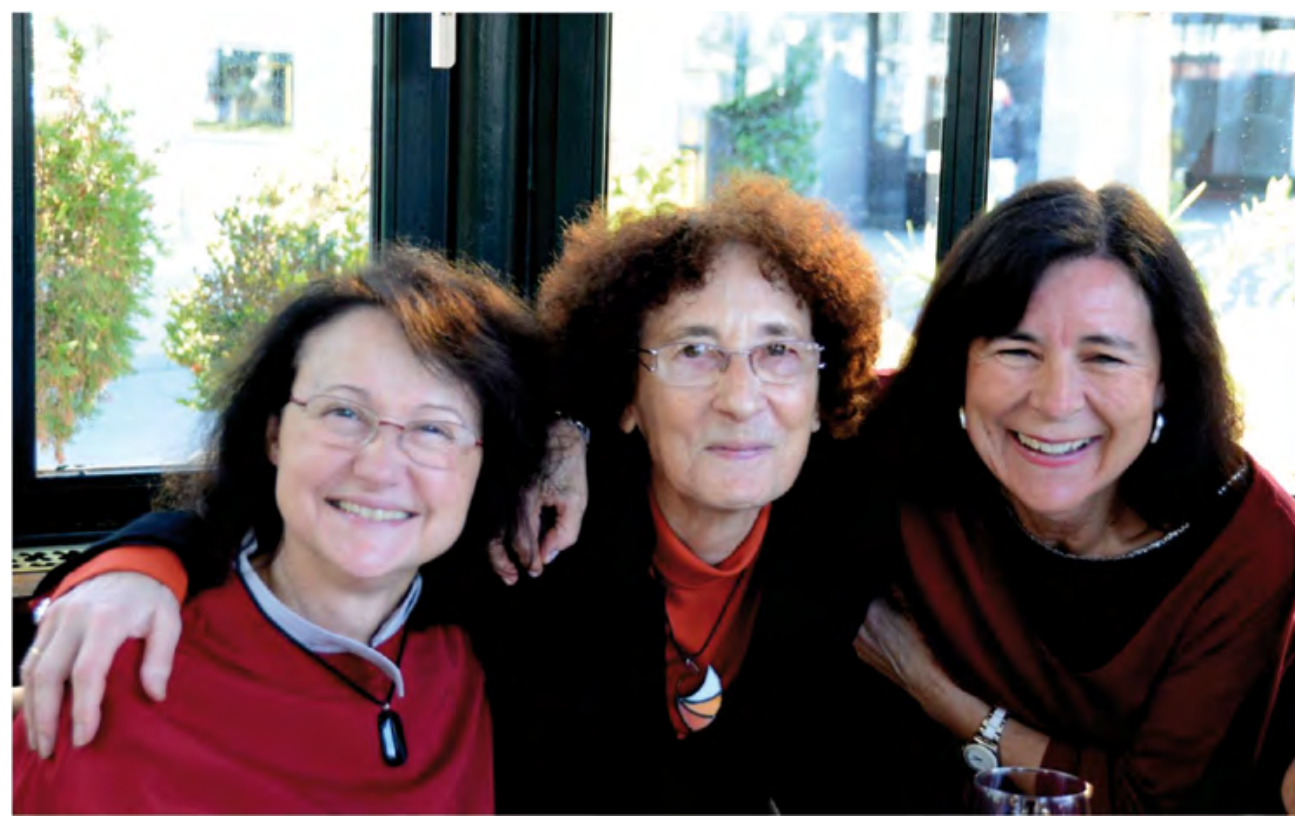

Alicia Alted, Rose Duroux y Teresa Valdehita, historiadora y directora del archivo de la UNED, diciembre de 2017

largo de la segunda mitad del siglo xx hicieron los Brauner para ayudar a niños víctimas de conflictos bélicos en distintas partes del mundo a través de los dibujos, y contribuyó a la puesta en marcha del proyecto EVE: Enfance, Violence, Exil, auspiciado por la Universidad de Clermont-Ferrand, en la que Rose había impartido docencia durante muchos años.

Otro tema para nosotros muy interesante, y que también has estudiado, es el de la maternidad de Elna, en Francia, donde nacieron tantos niños, hijos de refugiadas españolas de la guerra civil. ¿Podrías relatarnos algo sobre esta experiencia?

Ya he indicado cómo todo lo relativo a los niños me ha interesado desde que inicié mi carrera investigadora. Lo abordé en la tesis doctoral desde el punto de vista educativo y luego lo fui trabajando desde diferentes perspectivas y enfoques. En el año 2009 organizamos desde la UNED, como ya señalé también, una serie de actos conmemorativos del 70 aniversario del exilio. Uno de los aspectos que programamos fue algo que estaba impulsando mucho Mercedes Boixareu —entonces estaba ella como Vicerrectora de Extensión Cultural y yo estaba como Vi- 
cerrectora Adjunta de Relaciones Internacionales-, que eran las Rutas Literarias. Concebimos una Ruta del Exilio y en el diseño de esa Ruta del Exilio es cuando descubrí la maternidad. Sinceramente reconozco que hasta entonces no había tenido conocimiento de su existencia. Fuimos a visitarla, establecimos contacto con el entonces alcalde, Nicolás García y su equipo, que habían llevado a cabo todo el proyecto de adquisición del castillo de Bardou donde se alojó la maternidad y estaban inmersos en el proceso de difusión y rehabilitación del mismo.

Pensamos en la posibilidad de colaborar con ellos. Para ello elaboramos un proyecto desde AEMIC, la Asociación para el Estudio de los Exilios y las Migraciones Ibéricas Contemporáneas que habíamos fundado en 1996 y de la que era en ese momento presidenta Dolores Fernández y yo estaba en la Junta Directiva. Era el año 2010 y AEMIC, junto con la UNED, donde estaba entonces la sede de la Asociación, y la alcaldía de Elna, presentó a Presidencia del Gobierno el proyecto para hacer una exposición, celebrar un seminario y elaborar un libro. Nos aprobaron el proyecto y nos pusimos manos a la obra.

La exposición la inauguramos en octubre de 2012 en el vestíbulo de la Biblioteca Central de la UNED y, en el marco de la misma se proyectó el documental que se había realizado también con este motivo: La Maternidad Suiza de Elna, lugar de memoria y vida. En este documental trazamos visualmente la historia de la Maternidad con la ayuda y testimonio de los «niños» que nacieron en ella, y detallamos el proceso de rehabilitación exterior del edificio que se estaba llevando a cabo. La exposición se llevó a diferentes lugares y se clausuró en junio del 2016 en la sede del Parlamento Europeo en Bruselas. En 2014 se editó por la UNED el libro donde se recogían las intervenciones del seminario y el documental.

Cuéntanos qué fue la maternidad de Elna, qué papel cumplió para el exilio.

El Servicio Civil Internacional Suizo era una de las diversas organizaciones humanitarias que vinieron a España durante la guerra con el objetivo de ayudar a la población civil y muy en particular a los niños. Cuando terminó la guerra los voluntarios del Servicio Civil Internacional, que en su mayor parte eran mujeres, marcharon otra vez a sus lugares de residencia. Ante la situación en la que estaban los exiliados españoles en los llamados campos de la playa en Francia, y dado que ya 
se preveía que iba a desencadenarse una guerra en Europa, el Servicio Civil volvió a llamar a sus voluntarios para que vinieran a Francia a ayudar, primero a los españoles que estaban en los campos, y luego, cuando se desencadenó la Guerra Mundial a partir de septiembre de 1939, a toda la población posible que se encontraba en Francia en situación de desamparo. El cuartel general del Servicio Civil Internacional estuvo en Toulouse y centraron sus tareas, sobre todo en los primeros tiempos, en la ayuda a las mujeres embarazadas y a los niños que estaban en los campos. Los niños se morían, no tenían perspectiva de futuro ninguna.

Ante esa situación, el secretario general de lo que entonces se llamaba Ayuda Suiza a los niños víctimas de la guerra, Rodolfo Olgiati, encargó a Karl Ketterer y a varias voluntarias, entre ellas Elisabeth Eidenbenz, la posibilidad de alquilar un edificio en el sur de Francia, cerquita de los campos, donde se acogiera a mujeres embarazadas para que pudieran dar a luz en unas condiciones idóneas y estar allí los dos o tres primeros meses más críticos. Este es, pues, el origen de la maternidad. En un primer momento fueron acogidas mujeres españolas, pero luego empezaron a ir mujeres procedentes de otros países; hubo mujeres de hasta de 22 nacionalidades. A partir de 1942 se planteó un problema con el tema de los niños judíos, porque el gobierno suizo impuso el principio de la neutralidad y no quería indisponerse con el gobierno alemán. Sin embargo, en la maternidad de Elna se trató de proteger y de ayudar, no sin fuertes dificultades, a las mujeres judías, y nacieron allí sus hijos a los que incluso se les ponían nombres españoles para protegerles. La maternidad hizo una labor verdaderamente importante. Nacieron más de 600 niños y estuvo funcionando hasta la primavera de 1944, en que les avisaron que tenían que marcharse porque iba a ir la Gestapo; ya estaba el ejército alemán en retirada y les podía pasar cualquier cosa. Entonces huyeron y se establecieron en un edificio en Montagnac, y allí estuvieron hasta el año 46. Pero ya era otra cosa, realmente la maternidad en cuanto tal existió hasta abril de 1944.

También has estudiado otras instituciones de ayuda humanitaria durante conflictos bélicos, ¿no es cierto?

En realidad un tema te va llevando a otro. El contacto con la maternidad es lo que me llevó a querer estudiar más en profundidad cómo 
había sido la labor de ayuda humanitaria no solo durante la guerra civil, sino también en los años de la Segunda Guerra Mundial en Francia. Eso es lo que me llevó a tomar contacto con una serie de investigadores a los que propuse la presentación de un proyecto de $\mathrm{I}+\mathrm{D}$ sobre ayuda humanitaria en situación de conflicto bélico y en aspectos relacionados con este tema estamos trabajando desde 2014.

Esto nos lleva al final, porque lamentablemente no podemos extendernos más, pero quiero preguntarte por la creación en la UNED del Centro de Estudios de Migraciones y Exilios (CEME), que tiene su sede tanto en México como en Madrid. ¿Cómo surgió esta iniciativa y cuáles han sido sus logros más importantes?

El CEME fue una idea que vino a través de María Luisa Capella, hija de refugiados españoles en México donde había nacido. María Luisa estaba casada con el poeta Tomás Segovia y nos conocíamos desde hacía años. Ella tenía muy clara la idea de lo que debía ser ese centro. Empezamos a hablarlo a finales del 2009 cuando José Francisco Álvarez era vicerrector de Relaciones Internacionales e Institucionales y por mi parte estaba como vicerrectora adjunta en ese Vicerrectorado. Entre las dos diseñamos lo que podría ser ese Centro de Migraciones y Exilios. Lo presentamos al vicerrector y al entonces rector Juan Gimeno y les pareció bien. Se redactó un convenio de patrocinio del Centro por parte de la UNED y el Banco de Santander; se formó un patronato y se redactó el reglamento interno de funcionamiento. Del patronato formaba también parte el presidente del Ateneo Republicano Español de México, que en esos momentos era Carlos Vélez. La inauguración del Centro se hizo en la sede del Centro de la UNED en ciudad de México, un palacete precioso de la época del porfiriato, que acogió en el mismo edificio al CEME. Allí también se había ubicado la sede del Ateneo con su importante biblioteca y archivo.

La ayuda económica que recibimos nos permitió empezar a desarrollar toda una serie de actividades; la más importante ha sido consolidar el Certamen Internacional de Cine Documental sobre Migración y Exilio, el CEMEDOC, que este año ha celebrado su sexta edición y que ya tiene en México una presencia importante en el ámbito de los certámenes de documentales. Abrimos también una línea de publicaciones con la UNED y otras editoriales, como la colección de Clásicos de la Educa- 


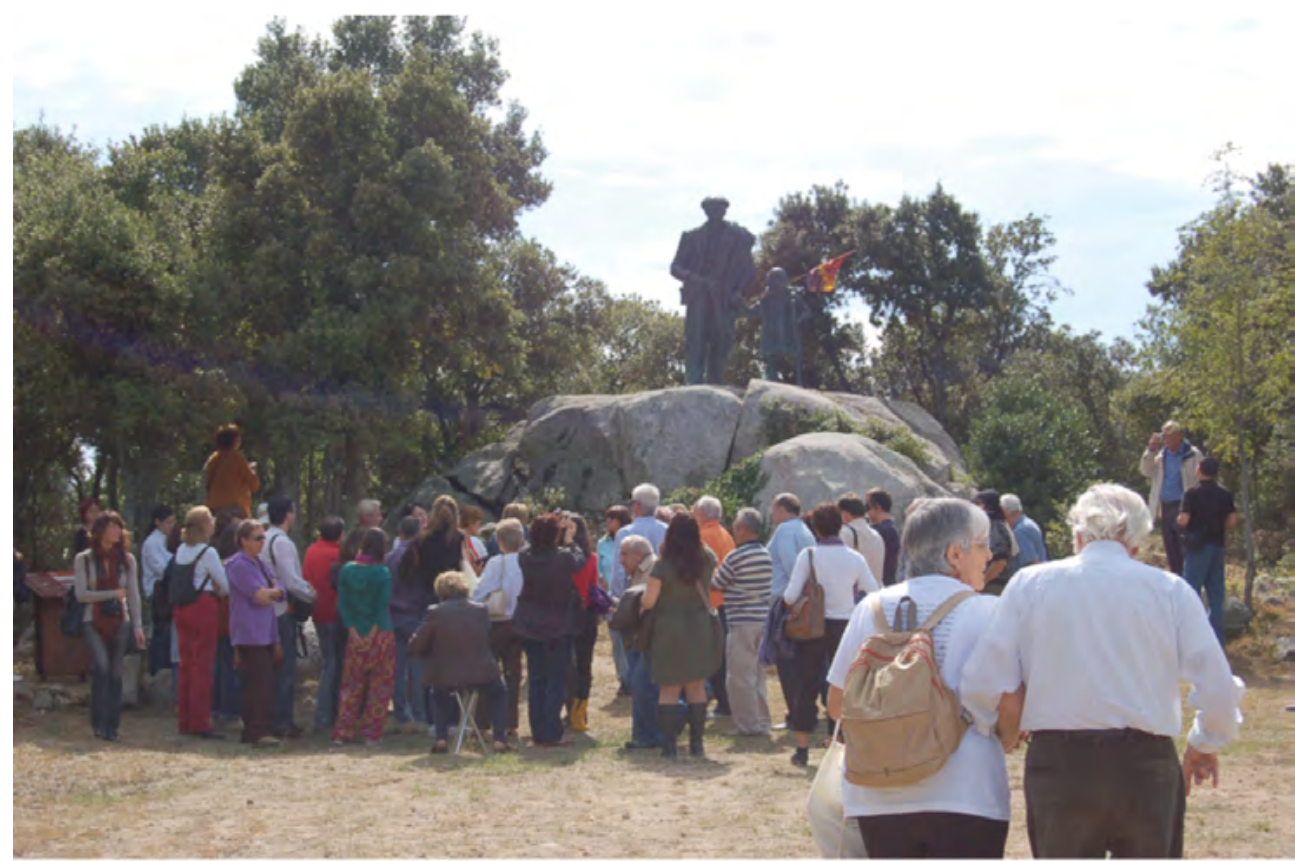

Ruta del Exilio, organizada por el Centro de Estudios de Migraciones y Exilios de la UNED en 2009. Frente al monumento al exilio aparecen de espaldas el poeta Tomás Segovia y María Luisa Capella.

ción de la editorial Biblioteca Nueva, con la que hemos publicado ese libro tan interesante sobre Herminio Almendros, y otro de Emilia Elías de Ballesteros. Con la UNED publicamos el diario de Conchita Simarro, una niña que empezó a escribirlo con 11 años en Barcelona en 1938 y lo interrumpió en México en 1944, o el epistolario entre Luis Amado Blanco, exiliado en Cuba, y David Arias que vivió su exilio en México.

Las labores del CEME son la investigación, la recuperación archivística y la difusión. La labor de recuperación de archivos ha sido muy importante; el último archivo recuperado fue el de Luis Amado Blanco, que se depositó en el archivo de la Fundación Pablo Iglesias en junio de este año de 2018. Pero hemos recuperado, como bien sabes, otros archivos. Uno de ellos, aunque no tiene relación directa con el exilio, se recuperó cuando la sede en Madrid del CEME se instaló en el Centro Asociado de la UNED Giner de los Ríos, en el edificio del que había sido el Grupo Escolar Giner de los Ríos durante la República, y que luego pasó a ser el Colegio Andrés Manjón. Allí se descubrió un archivo que, a través del 
CEME, se recuperó y se catalogó, y luego se hizo una exposición que ha tenido su trascendencia, sobre el origen del centro escolar desde que se fundó en el año 1933 hasta que pasó a ser Centro Asociado de la UNED.

Creo que en ese sentido la labor del CEME es importante y ha contribuido, y sigue contribuyendo, a un mejor conocimiento de las múltiples facetas del exilio en sus diferentes aspectos culturales, educativos, sociales y políticos. En ese sentido, cumple un importante papel y ojalá que como tal centro pueda seguir. Tiene adscrito un grupo consolidado de investigación sobre Migraciones y Exilios en el Mundo Contemporáneo, con el que hemos conseguido dos contratos Juan de la Cierva y dos contratos postdoctorales, lo cual es importante porque suponen la incorporación de jóvenes investigadores que ayudan en las actividades que se promueven desde el CEME.

Y eso es todo, Gabriela, podríamos seguir hablando de muchas otras cosas, entre ellas de proyectos en los que hemos trabajado juntas desde que nos conocemos, pero bueno, quizás en otra ocasión. Gracias de veras por haberte interesado en hacerme esta entrevista.

\section{SELECCIÓN DE PUBLICACIONES DE ALICIA ALTED}

\section{Libros como autora única}

- La Revista Filosofía y Letras, 1915-1920 (Aproximación a la vida universitaria española en las primeras décadas del siglo). Prólogo de Pedro Sainz Rodríguez. Madrid: Fundación Universitaria Española, 1981.

- Política del nuevo Estado sobre el patrimonio cultural y la educación durante la guerra civil española. Prólogo de Javier Tusell. Madrid: Ministerio de Cultura, 1984.

- El Archivo de la República Española en el exilio, 1945-1977. Prólogo de Juan Marichal. Madrid: Fundación Universitaria Española, 1993.

- La voz de los vencidos. El exilio republicano de 1939. Madrid: Editorial Aguilar, 2005.

\section{Libros en colaboración}

- Los niños de la Guerra de España en la Unión Soviética. De la evacuación al retorno (1937-1997). Madrid: Fundación Francisco Largo Caballero1999. Coautora junto con Encarna Nicolás y Roger González. 
- Disidencias en el franquismo (1939-1975). Murcia: Diego Marín Librero Editor, 1999. Coautora junto con Encarna Nicolás.

- La cultura del exilio anarcosindicalista español en el Sur de Francia. Madrid: Ediciones Cinca, 2012. Coautora junto con Lucienne Domergue.

\section{Edición de libros colectivos}

- La oposición al régimen de Franco. Madrid: UNED, 1990, 2 tomos, tomo 1 en 2 vols. Coeditora junto con Javier Tusell y Abdón Mateos

- Triunfo en su época. Madrid: Casa de Velázquez/Ediciones Pléyades, 1995. Coeditora junto con Paul Aubert.

- Manuel Azaña. Pensamiento y Acción. Prólogo de Enrique de Rivas. Madrid: Alianza, 1996. Coeditora junto con Ángeles Egido y María Fernanda Mancebo.

- Literatura y cultura del exilio español de 1939 en Francia. Salamanca: AEMIC-GEXEL Editores, 1998. Coeditora junto con Manuel Aznar Soler.

- Entre Memorias. Las finanzas del gobierno republicano en el exilio. Sevilla: Renacimiento, 2002. Coeditora junto con Virgilio Botella Pastor. Introducción y notas de Virgilio Botella Pastor.

- El exilio republicano español en Toulouse, 1939-1999. Madrid/Toulouse: UNED/Presses Universitaires du Mirail, 2003. Coeditora junto con Lucienne Domergue.

- Memorias de una niña de la guerra. Gijón: Ayuntamiento de Gijón, 2003. Coeditora Roger González y Jesús Suárez. Edición, introducción y notas a la obra de Isabel Argentina Álvarez Morán

- La cultura del exilio republicano español de 1939. Madrid: UNED, 2003, 2 vols. Codirectora junto con Manuel LLusia.

- De la España que emigra a la España que acoge. Madrid: Fundación Francisco Largo Caballero / Caja Duero, 2006. Coeditora junto con Almudena Asenjo

- Tiempos de exilio y solidaridad. La maternidad suiza de Elna (1939-1944). Madrid / Ville d'Elne: UNED / Alcaldía de Elne / DAME / AEMIC, 2014. Coeditora junto con $\mathrm{M}^{\mathrm{a}}$ Dolores Fernández.

- Cine educativo y científico en España, Argentina y Uruguay. Madrid: Editorial Universitaria Ramón Areces, 2016. Coeditora junto con Susana Sel.

\section{Catálogos de exposiciones}

- El exilio español en la guerra civil: Los niños de la guerra. Madrid: Ministerio de Cultura/Fundación Francisco Largo Caballero, 1995. Editora. 
- El exilio de los niños. Madrid: Fundación Pablo Iglesias y Fundación Francisco Largo Caballero, 2003. Coeditora junto con Roger Gonbzález y María José Millán.

- A pesar de todo dibujan. La Guerra Civil vista por los niños. Madrid: Biblioteca Nacional, 2006. Coeditora junto con Roger González.

- Infancia. Literatura y exilio del 39. Libros de la colección de Ana Pelegrín. Madrid: Gráficas Loureiro, 2009. Coeditora junto con María García Alonso y Gabriela Ossenbach.

\section{Capítulos de libros}

- «Notas para la configuración y el análisis de la política cultural del franquismo en sus orígenes». En España bajo el franquismo, editado por Josep Fontana, 214-229. Barcelona: Crítica, 1986.

- «La mujer en las coordenadas educativas del régimen franquista». En Ordenamiento jurídico y realidad social de las mujeres, siglos XVI a XX, 425-437. Madrid: Universidad Autónoma, 1986.

- «Poesía de guerra y nueva poesía durante el periodo de 1936-1939 en España». En Miscelánea-homenaje en honor de Pedro Sainz Rodríguez, tomo 3, 25-36. Madrid: Fundación Universitaria Española, 1987.

- «Las Españas y Diálogo de las Españas. Integración nacional y recuperación de la continuidad de la cultura española en el exilio, 1946-1963». En El destierro español en América. Un trasvase cultural, compilado por Nicolás Sánchez Albornoz, 219-233. Madrid: Instituto de Cooperación Ibero-Americana/Ediciones Siruela, 1991.

- «Les exilés espagnols en France: structures associatives, politiques et sindicales». En Italiens et espagnols en France, 1938-1946, dirigido por P. Milza y D. Pechanski, 441-458. París : C.N.R.S., 1991.

- «The Government of the Spanish Republic in Exile, 1939-1977». En Governments-in-Exile in Contemporary World Politics, editado por Y. Shain, 145-165. New York and London: Routlege, 1991. Coautora junto con Javier Tusell.

- «Bases político-ideológicas y jurídicas de la Universidad Franquista durante los Ministerios de Pedro Sainz Rodríguez y primera época de José Ibáñez Martín, 1938-1945». En La universidad española bajo el régimen de Franco, editado por J.J. Carreras y M.A. Ruiz Carnicer, 95-124. Zaragoza: Institución Fernando el Católico, 1991.

- «Modelli culturali e organizzazione istituzionale della cultura nella zona republicana e franchista». En Spagna anni 30. Società, cultura, istituzioni, editado por G. Di Febo y C. Natoli, 313-329. Milano: Franco Angeli, 1993. 
- «La oposición republicana, 1939-1977». En El republicanismo en España, 1830-1977, compilado por N. Townson, 223-262. Madrid: Alianza Editorial, 1994.

— «La Republique Espagnole, 1936-1946: Exil et reconstitution des institutions de l'État et des régions autonomes. Le gouvernement de José Giral». En Exil et Migration. Italiens et espagnols en France, 1938-1946, dirigido por P. Milza y D. Pechanski, 503-515. París: Editions L'Harmattan, 1994.

- «Fernando Valera y el Diálogo de las Españas». Libro-homenaje a Antonio de Béthencourt Massieu, 89-99. Las Palmas de Gran Canaria: Ediciones del Cabildo Insular de Gran Canaria, 1995.

- «The Republican and Nationalist Wartime Cultural Apparatus», «Education and Political Control», "Educacional Policy in a Changing Society», «Educacional Policy in Democratic Spain». En Spanish Cultural Studies. An Introduction (The Struggle for Modernity), editado por H. Grahan y J. Labanyi, 152-161, 196-201, 271-276 y 320-325. Oxford: University Press, 1995.

- «Trayectoria de una anarcosindicalista sevillana hasta 1939: el testimonio de Maravillas Rodríguez». En Entre la marginación y el desarrollo: Mujeres y hombres en la historia. Homenaje a María Carmen García-Nieto, editado por C. Segura y G. Nielfa, 229-248. Madrid: Ediciones del Orto, 1996. Coautora junto con M. G. Núñez.

- "Las consecuencias de la guerra civil española en los niños de la República: de la dispersión al exilio». En Le guerre dei bambini. Da Sarajevo a Sarajevo, editado por M.C. Giuntella e I. NardI, 207-227. Napoli: Edizioni Scientifiche Italiane, 1998.

- «L'entr'aide espagnole et franco-espagnole». En L'exil republicain espagnol à Toulouse, 1939-1999, editado por Lucienne Domergue, 61-75. Toulouse : Presses Universitaires du Mirail, 1999.

- «Le retour en Espagne des enfants évacués pendant la guerre civile espagnole: la Délégation extraordinaire au rapatriement des mineurs (19381954)». En Enfants de la guerre civile espagnole. Vécus et représentations de la génération née entre 1925 et 1940, 47-59. París: Centre d'Histoire de L’Europe du Vingtième Siècle/L'Harmattan, 1999.

- "Memoria e Historia novelada en la obra de Virgilio Botella Pastor». En Sesenta años después. Os Escritores do Exilio Republicano, editado por X. L. Axeitos y Ch. Portela, 251-267. A Coruña: Edicios do Castro, 1999.

- «México y las instituciones de la República española en el exilio». En Los refugiados españoles y la cultura mexicana, 319-339. México/Madrid: El Colegio de México/Residencia de Estudiantes, 1999.

- «Los niños de la guerra civil española: de la memoria a la historia». En La Numancia errante. Exilio republicano de 1939 y patrimonio cultural, editado 
por J.I. Cruz Orozco y M.J. Millán, 65-90. Valencia: Biblioteca Valenciana, 2002.

- «Historiadores e historiografía en el exilio». En Encuentros de Historia y Literatura. Max Aub y Manuel Tuñón de Lara, editado por M.F. Mancebo, 151168. Valencia: Biblioteca Valenciana, 2003

- «Virgilio Botella Pastor y la gestión económica de la República en el exilio». En Los grandes olvidados. Los republicanos de izquierda en el exilio, editado por A. Egido y M. Eiroa, 323-345. Madrid: C.I.E.R.E., 2004.

- «Les souffrances de la population civile». En Républicains espagnols en Midi-Pyrénees. Exil, Histoire et Memoire, 109-113. Toulouse: Presses Universitaires du Mirail, 2004.

- «La memoria de la República y la Guerra Civil en el exilio». En Memoria de la Guerra y del Franquismo, dirigido por Santos Juliá, 247-277. Madrid: Taurus/Fundación Pablo Iglesias, 2006.

- «La mujer en el exilio americano». En Ernestina de Champourcín. Mujer y cultura en el siglo XX, editado por R. Fernández Urtasun y J.A. Ascunce, 331342. Madrid: Biblioteca Nueva, 2006.

- «En torno a la identidad del exiliado republicano de 1939 y de sus culturas». En O exilio galego de 1936: Política, Sociedade, Itinerarios, editado por J.M. Núñez Seixas y P. Cagiao Vila, 67-77. A Coruña: Edicios do Castro, 2006.

- «Carmen Caamaño: una mujer en la vanguardia de su tiempo». En Historia, politica y cultura. Homenaje a Javier Tusell, editado por J. Avilés Farré, tomo II, 175-186. Madrid: UNED, 2009.

- «La creación de un Archivo Oral». En Testigos de la Historia II. Estudios sobre fuentes documentales, coordinado por M.C. Ybarra, 161-181. Madrid: Fundación Carlos de Amberes, 2009.

- «La mujer en el cine durante la guerra civil española». En Ciudadanas y protagonistas históricas. Mujeres republicanas en la II República y la Guerra Civil, coordinado por M. Nash, 187-200. Madrid: Departamento de Publicaciones del Congreso de los Diputados, 2009.

- «El exilio de los anarquistas». En Tierra y Libertad. Cien años de anarquismo en España, coordinado por J. Casanova, 167-190. Barcelona, Crítica, 2010.

- «En el balcón vacío ou la recontre entre écriture filmique et écriture historique». En Le enjeux du cinéma espagnol. De la guerre à la postmodernité, dirigido por V. Sánchez-Biosca y V.J. Benet, 183-191. Paris: L'Harmattan, 2010.

- «Historiadores españoles exiliados en América Latina». En El exilio republicano español en México y Argentina. Historia cultural, Instituciones literarias, Medios, editado por A. Pagni, A., 77-92. Madrid: Iberoamericana / Vervuert, 2011. 
- «Los estudios del exilio a revisión: de las emigraciones políticas liberales del siglo xIX a los exilios de masas del siglo xx. España y América Latina en perspectiva comparada». En Nuevos horizontes del pasado. Culturas políticas, identidades y formas de representación, editado por A. Barrio Alonso, J. de Hoyos Puente y R. Saavedra Arias, 117-126. Santander: Publicaciones de la Universidad de Cantabria, 2011. Coautora junto con Jorge de Hoyos Puente.

- «El paso de frontera como ruptura en las mujeres exiliadas». En Mujeres en la frontera, coordinado por M. Almela et al., 39-52. Madrid: UNED, 2013.

- «Repatriation or Return? The Difficult Home-Coming of the Spanish Civil War Exiles». En Coming Home? Vol. 1: Conflict and Return Migration in the Aftermath of Europe's Twentieth-Century Civil Wars, editado por Sh. Gemei y S. Soo. Newcastle upon Tyne: Cambridge \&Scholars Publishing, 2013.

\section{Artículos de revista}

- «Prensa ilustrada en la España del siglo XviII. El Apologista Universal, 17861788». Cuadernos para la Investigación de la Literatura Hispánica 6 (1984): 141-179

- «El testimonio oral como fuente histórica. Aproximación metodológica». Perspectiva Contemporánea. España siglo XX 1 (1988): 155-162.

- «La política cultural del franquismo. Líneas generales de análisis y estado de la cuestión». Bulletin d' histoire contemporaine de l' Espagne 11-12 (1990): 16-26.

- «La Cruz Roja Republicana Española en Francia, 1945-1986». Revista de Historia Contemporánea (Bilbao) 6 (1991): 223-249.

- «Gobiernos y partidos republicanos españoles en el exilio, 1950-1962». Melanges de la Casa de Velázquez, tomo XXVII, 3 (1991): 85-114.

- «Problemas de método en el estudio de la oposición al franquismo. La utilización del testimonio oral». Espacio, Tiempo y Forma. Serie V, Historia Contemporánea tomo III, vol. 2 (1990): 57-68. Coautora junto con Abdón Mateos.

- «José Maldonado, vivencias y pensamiento político de un republicano español»(Entrevista). Cuadernos Republicanos 16 y 17 (1993 y 1994): 25-42 y 15-39.

- «La guerra civil española y los niños». Espacio, Tiempo y Forma. Serie V, Historia Contemporánea, tomo 9 (1996): 207-228.

- «El exilio republicano español de 1939 desde la perspectiva de las mujeres». Arenal vol. 4, 2 (1997): 223-238.

- «En el balcón vacío o la confluencia entre escritura fílmica y escritura histórica». Archivos de la Filmoteca (Valencia) 33 (1999): 130-139. 
- «Científicos españoles exiliados en Cuba». Revista de Indias 224 (2002): 173-194. Coautora junto con Roger González.

— «El exilio español en la Unión Soviética». Ayer 47 (2002): 129-154.

- «Los niños de la Guerra Civil». Anales de Historia Contemporánea (Universidad de Murcia) 19 (2003): 43-58.

— «El cine educativo en España (hasta 1936)». Historia Social 76 (2013): 91-106.

\section{SELECCIÓN DE TESIS DOCTORALES DIRIGIDAS POR ALICIA} ALTED EN EL DEPARTAMENTO DE HISTORIA CONTEMPORÁNEA DE LA UNED

Alicia Pascual (1991). La enseñanza primaria en la provincia de Madrid en el siglo XIX.

Rosalía Crego Navarro (1993). El Ministerio de Instrucción Pública durante la guerra civil española.

Manuel Vizuete Carrizosa (1996). La educación física y el deporte escolar en el franquismo

Julio Escribano (1998). Pedro Sainz Rodríguez. De la Monarquía a la República.

Inmaculada Colomina Limonero (2008). Dos patrias, 3000 destinos: Vida y exilio de los niños de la Guerra de España refugiados en Rusia.

Tamar Groves (2010). El movimiento de Enseñantes durante el Tardo-franquismo y la Transición a la Democracia, 1970-1983.

Emilio Ruiz (2016). Una Universidad posible en tiempos de Jaime Benitez (19421972). Los intelectuales españoles acogidos en la Universidad de Puerto Rico a raíz de la Guerra Civil española (1936-1939).

Juan Carlos Collado (2016). Los evacuados de la Guerra Civil de la provincia de Toledo (1936-1940).

\section{PUBLICACIONES DEL CENTRO DE ESTUDIOS DE MIGRACIONES} Y EXILIOS (CEME)

\section{En la Editorial UNED (Serie Migraciones Contemporáneas)}

- Alted Vigil, Alicia y Roger González (eds.). David Arias y Luis Amado-Blanco: De Francia a México, con Cuba en el horizonte. Epistolario (19391969). Madrid: Editorial UNED, 2018.

- Alted Vigil, Alicia y Roger González (guión y dirección). El exilio español en Cuba. Una doble mirada (documental). Madrid: Editorial UNED, 2016.

- Barroso, Gonzalo. La dictadura de Pinochet a través del cine documental 1973-2014. Madrid: Editorial UNED, 2018. 
- Estrade, Paul (dir.). El trabajo forzado de los españoles en la Francia de Vichy. Los grupos de trabajadores extranjeros en Corrèze (1940-1944). Madrid: Editorial UNED, 2016.

- López Rodríguez, Armando (ed.). Andanzas del piloto republicano Fernando Puig. Madrid: Editorial UNED, 2018.

- Marco, Miguel. La injusticia de un olvido. El mundo de Marcelino Pascua. 1897-1977. Madrid: Editorial UNED, 2018.

- Martínez Cobo, José María. El Socorro Suizo a los niños de la zona sur de Francia (1939-1947). El informe Parera. Prólogo de Alicia Alted Vigil. Madrid: Editorial UNED, 2017.

- Simarro, Conxita. Diario de una niña en tiempos de guerra y exilio (19381944). Prólogo de Rita Arias Simarro, estudios introductorios de Alicia Alted Vigil y Susana Sosenski. Madrid / México: Editorial UNED, 2015.

\section{En la colección Clásicos de la Educación (Biblioteca Nueva / SEDHE)}

- Almendros, Herminio. La escuela moderna. ¿Reacción o progreso?. Edición de Roger González Martell. Madrid: Biblioteca Nueva, 2016.

- Elías de Ballesteros, Emilia. Problemas educativos actuales. Edición de José Ignacio Cruz Orozco y Alicia Civera Cerecedo. Madrid: Biblioteca Nueva, 2017.

- Hernández Ruiz, Santiago. La escuela unitaria completa. Edición de Gabriela Ossenbach. Madrid: Biblioteca Nueva, en prensa.

\section{Nota sobre la autora}

Gabriela Ossenbach Sauter es catedrática de Historia de la Educación Contemporánea en el Departamento de Historia de la Educación y Educación Comparada, y directora del Centro de Investigación MANES de la Universidad Nacional de Educación a Distancia (UNED). 